\title{
Measuring Heterogeneity in Job Finding Rates among the Non-Employed Using Labor Force Status Histories
}

\author{
Marianna Kudlyak \\ Federal Reserve Bank of San Francisco \\ Fabian Lange \\ McGill University \\ IZA \\ January 2018 \\ Working Paper 2017-20
}

http://www.frbsf.org/economic-research/publications/working-papers/2017/20/

\section{Suggested citation:}

Kudlyak, Marianna, Fabian Lange. 2018. “Measuring Heterogeneity in Job Finding Rates among the Non-Employed Using Labor Force Status Histories” Federal Reserve Bank of San Francisco Working Paper 2017-20. https://doi.org/10.24148/wp2017-20

The views in this paper are solely the responsibility of the authors and should not be interpreted as reflecting the views of the Federal Reserve Bank of San Francisco or the Board of Governors of the Federal Reserve System. 


\title{
Measuring Heterogeneity in Job Finding Rates among the Non-Employed Using Labor Force Status Histories
}

\author{
Marianna Kudlyak \\ Federal Reserve Bank of San Francisco
}

\author{
Fabian Lange \\ McGill University and IZA
}

This Draft: January 22 ${ }^{\text {nd }}, 2018$

First Draft: May 20 ${ }^{\text {th }}, 2014$

\begin{abstract}
We construct a novel measure of the duration of joblessness using the labor force status histories in the four-month CPS panels. For those out of the labor force (OLF) and the unemployed, the job finding rate declines with the duration of joblessness. This duration measure dominates other existing measures in the CPS for predicting transitions from non-employment to employment. For those OLF, the variation in job finding rates explained by the duration of joblessness is five times larger than the variation explained by the self-reported desire to work or reasons for not searching. For the unemployed, the job finding rate declines with the self-reported duration of unemployment only to the extent that this variable correlates with the duration of joblessness. The two duration measures are not equivalent, and the discrepancy between them is not a classification error. Instead, the self-reports of unemployment durations refer to how long the respondent looked for work, often disregarding short-term jobs or including periods of employment while searching. Using our novel measure, we provide new estimates of the duration distribution of the unemployed and reexamine current approaches to misclassification error in the CPS.
\end{abstract}

JEL: E24, E32, J30, J41, J63, J64

Keywords: Job Finding Rate. OLF. Unemployment. Duration of Joblessness. Heterogeneity. Misclassification Error.

We thank Jim Hamilton, our discussants Bart Hobijn and David Wiczer and the seminar and conference participants at the 2014 System Microeconomics Meeting at FRB Minneapolis, the 2015 FRB Cleveland-University of Kentucky Labor Workshop, the 2015 Society of Economics Dynamics Meeting in Warsaw, the 2015 Econometric Society Meeting in Montreal, the 2015 Society of Labor Economists Meeting in Montreal, the 2015 CADRE Workshop at FRB Kansas City, the 2015 System Microeconomics Meeting at FRB Dallas, the 2015 Midwest Macro Meetings, the A. Stockman Conference at the University of Rochester, Elon University, University of Montreal, the FRB Chicago, the FRB San Francisco, the 2017 FRB Macro-Labor Meeting, and the BLS for their useful comments. The authors thank Theodore Naff for expert editorial assistance. The views expressed here are those of the authors and do not necessarily reflect those of the Federal Reserve Bank of San Francisco, the Federal Reserve System, or any other institution with which the authors are affiliated. 


\section{Introduction}

To measure the potential for employment among the non-employed population is a central challenge of labor economics. To meet this challenge, much of the literature distinguishes between those out of the labor force (OLF) and the unemployed, using the latter as a measure of the population of job seekers. However, the majority of transitions to employment are by those OLF who make up $90 \%$ of the non-employed population. Capturing the potential for employment among the non-employed thus requires predicting employment transitions among those OLF. For the unemployed, the self-reported duration of unemployment has been shown to strongly predict transitions to employment. No corresponding duration information is available for those OLF. Standard measures to classify OLF - by self-reported desire to work and reasons for not searching - are weak predictors of future employment. Our paper strives to contribute to measuring employment potential for this group as well as to improve on existing predictors of transitions to employment among the unemployed.

The distinction between unemployment and OLF is by no means clear-cut but a matter of degree. ${ }^{1}$ The unemployed are those non-employed who report that they have actively searched for employment and been available for work during the current month. ${ }^{2}$ However, there are a number of difficulties with classifying the non-employed on the basis of these self-reports. First, an absence of active search during the current month is not necessarily informative about job search activities in preceding months. Specifically, theory suggests that passive search, or even "waiting," might also be productive activities for finding employment. ${ }^{3}$ Second, during the CPS Re-Interview Survey (conducted in 1980), the labor force status in the reference week of a substantial proportion of respondents had to be reclassified based on interviews conducted just one week after the original interview (Jones and Riddell, 1999). ${ }^{4}$ Relatedly, as we document below, 20\% of the unemployed who were employed last month and $50 \%$ of the unemployed who were OLF last month report durations of unemployment longer than one month. Clearly, the line separating different labor

\footnotetext{
${ }^{1}$ See Hall (1970) and Clark and Summers (1979) for a discussion of the ambiguity of the distinction.

${ }^{2}$ Active search is defined as a search method that could directly lead to a job offer. For instance, this could include responding to job ads by sending CVs but does not include simply looking at job advertisements. ${ }^{3}$ See the stock-flow search model of Coles and Smith (1998) or the "waiting at the airport" example of Hall (1983).

${ }^{4}$ See also Abowd and Zellner (1985) and Poterba and Summers (1986).
} 
market statuses is not as sharp as the common focus in the literature on the unemployed as the population of job seekers would lead one to believe.

In this paper, we propose a new measure of labor market attachment of the non-employed. Our approach exploits the short four-month panels available in the CPS. Specifically, we supplement contemporaneous-month information with the labor force statuses from the previous two months. Using the first three months of each four-month panel, we generate three-month sequences of labor force statuses ending in non-employment (unemployment or OLF) in the third month. We then study transitions from non-employment in month three to employment in month four conditional on the three-month histories of the non-employed ("LFS history").

Our main finding is that the duration of joblessness, as constructed using the LFS histories, is a far better predictor of transitions to employment than the self-reported duration of unemployment. This holds true for those OLF for whom self-reported duration of labor force status is not available. For the unemployed, we demonstrate that the self-reported duration of unemployment is only an imperfect proxy for the duration of joblessness.

The self-reported duration of unemployment captures how long individuals have been looking for work, not how long they have been jobless. We document that $20 \%$ of those unemployed who were employed last month report having been unemployed for longer than one month. More specifically, the unemployed are more likely to report longer unemployment durations after recent employment if the employment was short-term or if they started searching while still working. The reported durations are not erroneous: when respondents reenter unemployment after a short period of employment, they often report durations of unemployment that are consistent with the durations reported prior to the interrupting employment spell. Such responses are consistent with the concept of "the duration of looking for work," which corresponds to the actual question in the CPS that is used by analysts to code unemployment durations.

We find that the duration of joblessness is crucial for characterizing the dynamics of job finding rates among the non-employed. In particular, job finding rates decline with the duration of joblessness irrespective of whether we condition on the self-reported duration of unemployment. By contrast, the job finding rate declines with self-reported duration of unemployment only to the extent that this variable correlates with the duration of joblessness. Among those OLF, we 
demonstrate that the duration since last employment is the single most powerful predictor of future employment. The average OLF individual with recent employment, regardless of the self-reported desire for work, has as a job finding rate twice the magnitude of the average OLF individual who reports wanting a job. The majority of those wanting a job have histories with no recent employment, and thus low employment transition rates.

We identify a large group of OLF - corresponding to those recently employed - with a high employment transition rate (0.40). This rate is second only to the rate of the unemployed with recent employment (0.46), but much higher than the rate for other categories of the unemployed. The novelty of this stems from the fact that the existing classifications of the OLF by self-reported desire to work or reason for not searching do not permit the identification of an observable group among the OLF with the job finding rate higher than the rate of the unemployed (see, for example, Flinn and Heckman, 1983).

In addition, we find that not only the duration since previous employment but also the duration (continuity) of previous employment matters. That is, longer employment spells are associated with higher future employment transition rates. Consistent with the literature's use of the concept of OLF, we find that conditional on the labor force status history in the past two months, the unemployed have higher employment transition rate than the OLF. All of our documented regularities hold by detailed age, gender and education categories.

To illustrate the predictive ability of our LFS histories, we run a horse-race between the 18 LFS histories and the current-month detailed classification by duration and reason for the unemployed as well as the desire to work, reason for not actively looking for work, school attendance, retirement, disability of those OLF. The results of this horse-race confirm that LFS histories explain a much larger fraction of the variation in the employment transition rates than do the current month classifications. The explanatory power of these LFS histories derives from information on the duration since and the continuity of the most recent employment among the non-employed.

Using our proposed approach, we examine two applications in the labor literature. First, we challenge a common practice in the literature that treats transition reversals between unemployment and OLF as classification error, i.e., a "DeNUNification" procedure which recodes 
the unemployment-OLF cyclers into one of the two continuous non-employment statuses (Elsby, Hobijn, and Sahin, 2015). We test the hypothesis that frequent switching between labor force statuses represents pure classification error by comparing the job finding rates and re-employment wages of the non-employed with different LFS histories. We find that those OLF with recent unemployment have a job finding rate five times higher than those OLF for three consecutive months. The unemployed with recent OLF and the unemployed for three consecutive months have similar job finding rates but the former have lower wages upon reemployment. Consequently, these differences in outcomes rule out pure classification error as an explanation behind the frequent switches between unemployment and OLF. Instead, the data favor the interpretation that those who frequently change status between OLF and unemployment are less closely attached to the labor market than those who are consistently unemployed, but they are more closely attached than those consistently OLF. The quantitative implications of our findings are large: under "DeNUNification," the transition probabilities between OLF and unemployment drop by more than 35\% and between OLF and employment - by more than 55\% (see Figure 2, Elsby et al., 2015) as compared to the uncorrected data. By contrast, our findings show that the flows between labor market statuses are large and informative.

Second, reported unemployment durations are used in a variety of applications as if they were the distributions of unemployment or joblessness more broadly. ${ }^{5}$ Our findings strongly suggest that they are not. We propose to correct the distribution of reported unemployment durations by using the observed joblessness duration in the LFS histories rather than the reported durations whenever possible. Despite the relatively short panels in the CPS, correcting the distribution of reported unemployment goes a long way towards obtaining a more accurate estimate of the duration of joblessness among the unemployed. Our proposed duration distribution has a higher mass on short one-month durations. In Section 7.4 we show that it implies an average job finding rate of 0.31 , exceeding the 0.26 obtained using the conventional distribution of self-reported duration of unemployment.

\footnotetext{
${ }^{5}$ For a list of applications, see the literature on the "Ins and Outs" of unemployment, or on the ex-ante heterogeneity versus the true negative duration dependence in exit rates from unemployment (Hall, 2005, Fujita and Ramey 2009, Elsby, Michaels, and Solon, 2009, Shimer, 2012, Hornstein, 2012, and Ahn and Hamilton, 2016).
} 
Our work contributes to a long-standing literature that focuses on non-employment and factors associated with transitions from non-employment to employment. Following Flinn and Heckman (1983), most of the literature has focused on unemployment. Blanchard and Diamond (1990), Fallick and Fleischman (2004), Kudlyak and Schwartzman (2012), and Elsby, Hobijn, and Sahin (2015) also discuss the transitions to and from OLF. ${ }^{6}$ However, these studies do not explore LFS histories. Jones and Riddell (2006), Krueger, Cramer, and Cho (2014), and Hall and SchulhoferWohl (2018) explore the panel dimension of the labor force status surveys but limit themselves to transitions from the current-month LFS into employment over a few subsequent months. By contrast, we examine the LFS history. Our work is also related to the literature on negative duration dependence in exit from unemployment (Nickell, 1979; Hornstein, 2012; Ahn and Hamilton, 2014; Alvarez, Borovikova, and Shimer, 2014; Kroft, Lange, Notowidigdo, and Katz, 2016; and Fujita and Moscarini, 2017). We extend that literature to document the negative duration dependence for both the unemployed and those OLF.

To summarize, the prevailing approach in the existing literature to address the absence of clear distinction between OLF and unemployment centers on classification error. ${ }^{7}$ The classification error approach implies that there exists a sharp distinction between the unemployed and OLF and that it can be captured by the current-month information. In our work, we substitute LFS histories for the sharp distinction between search activity of the unemployed and those OLF. We find that supplementing current-month information of the non-employed with just two months of LFS, readily available in the CPS, uncovers a large and crucial dimension of heterogeneity within the non-employed population in terms of their labor market attachment.

The rest of the paper is structured as follows. Section 2 describes the construction of our LFS histories. Section 3 describes our findings on the employment transition rates. Section 4 applies the LFS histories approach to examine the labor market attachment of the unemployment-OLF

\footnotetext{
${ }^{6}$ Central to models in this literature is the theoretical construct of "job seekers." Only recently has the literature began to also consider those OLF (Veracietro, 2008; Krusell, Mukoyama, Rogerson, and Sahin, 2012; Elsby, Hobijn, Sahin, and Valletta, 2012; Diamond, 2013; Farber and Valletta, 2015; Rothstein, 2012; and Van Zandweghe, 2017).

${ }^{7}$ Abowd and Zellner (1985) and Poterba and Summers (1986) estimate the classification error based on the assumption that the Reconciled Subsample of the CPS Re-interview Survey contains "true" status. Feng and $\mathrm{Hu}$ (2013) restrict the measurement error structure to be Markovian. Elsby, Hobijn, and Sahin (2015) use a "DeNUNification" procedure.
} 
cyclers. Section 5 runs the horse race between the LFS histories and the information from the current month survey. Section 6 examines the self-reported labor market attachment and the LFS histories of those OLF. Section 7 compares the reported duration of unemployment versus the duration of joblessness in the labor force status histories. Section 8 concludes.

\section{Constructing Labor Force Status Histories in the CPS}

\subsection{The Non-Employment Concepts in the Current Population Survey}

The data in our analysis come from the Current Population Survey (CPS) basic monthly files covering the period from January 1976 to March 2017.

The CPS distinguishes between two groups of non-employed. According to the CPS Manual, the unemployed are those aged $16+$ who did not work at all during the reference week, who were not absent from a job, who actively looked for work during the past four weeks, and who were available for work during the reference week. Persons who were on layoff from a job to which they expect to return and were available for work during the reference week are also classified as unemployed, even if they did not actively look for work. ${ }^{8}$

The persons not in the labor force are those who “... did not work last week, was not temporarily absent from a job, did not actively look for work in the previous four weeks, or looked but was unavailable for work during the reference week; in other words, a person who was neither employed nor unemployed.” (The CPS Manual)

\subsection{The Labor Force Status Histories in the CPS}

We exploit the panel structure of the CPS to classify the non-employed based on their LFS history. In the CPS, respondents are interviewed for 4 consecutive months, after which they are not interviewed for 8 months, and finally they are interviewed again for 4 consecutive months. The interview months are labeled from 1 to 8, and are referred to as month-in sample (MIS, hereafter).

\footnotetext{
${ }^{8}$ The unemployed who are expected to return to a job are on layoff. The definition of layoff unemployment was tightened during the 1994 CPS redesign. After 1994, those on layoff must expect to be recalled to the job within 6 months or the employer must have given the person a specific date upon which they would be recalled in order to be counted as "unemployed" without actively searching for work.
} 
The monthly CPS file thus contains data from respondents in any of the eight interview months. We match the respondent's records across month-in-sample to obtain short four-month panels. ${ }^{9}$

We focus on the LFS histories of non-employed individuals - unemployed or OLF - in month three of the panels (i.e., in MIS-3 and MIS-7). We then study the employment transition rate from nonemployment in month three, conditional on the three-month LFS histories, to employment in month four. ${ }^{10}$ In order to generate population-representative samples, we re-weigh the data using the average of the CPS sampling weights in the third and fourth months of the four-month panels.

There are 18 possible LFS histories that have either unemployed (U) or OLF in the third month. We refer to the individual histories using sequences of statuses from $t-2$ to $t$, i.e., NEU is a history with OLF in $t-2$ (where $\mathrm{N}$ denotes being OLF), employment in $t-1$ and unemployment in $t$. There are six distinct subpopulations of non-employed based on the LFS histories: (1) unemployed, recently employed (EEU, EUU, UEU, ENU, NEU); (2) unemployed, not recently employed except UUU (NNU, NUU, UNU); (3) unemployed in the three consecutive months (UUU); (4) OLF, recently employed (EEN, ENN, NEN, EUN, UEN); (5) OLF, not recently employed except NNN (UUN, UNN, NUN); (6) OLF in the three consecutive months (NNN).

\section{Heterogeneity in Employment Transition Rates by Labor Force Status History}

In this section, we study how monthly transition rates from non-employment to employment vary with the LFS histories. We document that the rates of both the unemployed and those OLF decline with the length of time since last employment and that, conditional on the duration since last employment, the duration of last employment matters.

\subsection{The LFS Histories of the Non-Employed}

9 To match the individual records month-to-month, we follow Madrian and Lefgren (1999) and Shimer
(2012) and match individuals by race, age and sex besides individual and household ID. This approach
minimizes errors in matching across months that arise because the CPS uses a sample of addresses. Nekarda
(2009) proposes an alternative approach but finds little effect on job finding rates. Following the BLS
approach, we do not impute missing observations or address the issue of possible varying responses
conditional on the month in sample interview. We leave these questions for further research.
${ }^{10}$ Hereafter, we treat MIS 5 through MIS-8 in the same manner as MIS-1 through 4, except in Section 3.1.4. 
The non-employed differ by their labor force status in the previous two months (Table 3.1). Over the period 1976-2016, 35\% of the unemployed were recently employed in at least one of the two prior months, 36\% were continuously unemployed for at least three months, and the rest had some combination of unemployment and out of the labor force. Among those OLF, 87\% were continuously OLF for at least two months, $8 \%$ were employed in at least one of the two prior months, and the rest had some combination of unemployment and OLF. Some sequences of past labor force statuses are more common than others; but the relative ranking of the LFS histories by their prevalence in the population persists over time. ${ }^{11}$

Job finding rates exhibit substantial heterogeneity by LFS history. The differences in the employment transition rates by LFS history are not driven by age, gender, or education. ${ }^{12}$ This can be seen in Figure 3.1 that shows the average employment transition rates by LFS history with and without controls for demographics.

What stands out from Table 3.1 is that job finding rates are highest among those who were recently employed, regardless whether they are currently unemployed or OLF. ${ }^{13}$ Furthermore, job finding rates are the highest among those non-employed who were continuously employed in the two preceding months. These results suggest that the duration since recent employment and continuity of recent employment are important predictors of future transitions to employment.

\subsubsection{Duration since Recent Employment}

In this section, we formally show that job finding rates for both the unemployed and those OLF decline in the duration of joblessness (i.e., the time since the last recorded employment in the LFS histories). Table 3.2 reports estimates from a simple linear probability model of employment transitions, estimated separately for the unemployed, for those OLF, and for the pooled sample of the unemployed and OLF. ${ }^{14}$ Among the unemployed, those who have been jobless for only one

\footnotetext{
${ }^{11}$ See Appendix Figure A3.1 and Figure A3.2 for the time series of the shares of all 18 LFS histories in the civilian non-institutionalized population 16 years or older.

${ }^{12}$ However, the population shares of different LFS histories vary among different demographic groups.

${ }^{13}$ The ranking of the histories by transition rates persists over time as can be seen in Appendix Figure A3.3. The figure shows the time series of the annual averages of monthly transition rates from non-employment to employment by detailed LFS history from 1976 to 2016.

${ }^{14}$ Table 3.2, Columns 1-3 contain the results from a model with three dummies that indicate the duration since the most recent employment - an indicator for the most recent employment in month $t-1$, an indicator
} 
month are 1.6 times more likely to transition to employment the next month than those who have been jobless for two months. Moreover, they are more than three times more likely to transition to employment than those who have been jobless for at least two months. Among those OLF, individuals who have been jobless for only one month are on average twice more likely to transition to employment the next month than those who have been jobless for two months. Further, they are ten times more likely to transition to employment than those who have been jobless for at least two months.

These results are novel in two important respects. First, it is not possible to construct a duration measure of non-employment for those OLF using a traditional approach of employing the onemonth CPS data. Therefore, our findings based on the CPS panels are the first to document duration dependence among the OLF. Second, the CPS collects information on the duration of unemployment that have been analyzed extensively. However, in Section 7, we document that the reported duration of unemployment and the duration of joblessness often disagree and, more importantly, that the job finding rates decline with the duration of joblessness but not necessarily with reported duration of unemployment.

\subsubsection{Duration of the Recent Employment}

We find that not only the duration since recent employment matters for future transitions to employment but also the duration of recent employment. Conditional on duration of joblessness, those who were employed on a more continuous basis were more likely to transition back into employment than those who were only employed for a short period. ${ }^{15}$ For example, on average, $40 \%$ of those with the EEN histories transition back to employment within the next month compared to just $25 \%$ of those with the UEN histories (see Columns 4-6 in Table 3.2). ${ }^{16}$

\footnotetext{
for the most recent employment in month $t-2$, and an indicator for no employment in month $t-1$ and $t-2$ (additional controls include age, gender, education, year and seasonal dummies).

${ }^{15}$ Note that continuity of employment does not necessarily imply employment with the same employer.

16 Table 3.2, Columns 4-6 show the results from a linear probability model of employment transitions with four dummies that represent the nature of the previous employment captured by the LFS histories - an indicator for employment in month $t-1$ and $t-2$ (i.e., most recent and continuous employment), an indicator for employment in $t-1$ only, an indicator for employment in $t-2$ only, and an indicator for no employment in neither $t-1$ nor $t-2$. That is, we disentangle the first dummy in columns 1-3 into two dummies: one representing at least two months of employment and the other one representing only one month of employment.
} 


\subsubsection{Unemployment versus OLF, Conditional on the Prior LFS History}

Finally, conditional on their LFS histories, those who are currently unemployed have a higher job finding rate than those who are currently OLF (Table 3.3 and Appendix Figure A3.4).

If we do not condition on prior LFS history, an average unemployed also has a higher job finding rate than an average OLF. However, this represents a composition effect with respect to the LFS histories. Specifically, those OLF with recent employment have significantly higher job finding rates than the unemployed with no recent employment; but these OLF represent a small share of all the OLF. Most of the OLF are individuals who were OLF for three consecutive months and therefore have very low job finding rates (on average, 50\% of them are retired and 13\% are disabled over three consecutive months with job finding rates 0.006 and 0.007 , respectively). ${ }^{17}$

\subsubsection{Additional Evidence from the 8-month Panel}

Our key finding is that the duration since and the duration of recent employment are important factors that strongly correlate with transitions from non-employment to employment. In this subsection, we show that these findings are supported by data from the full 8-month individual panels available in the CPS.

To construct the 8-month panels, we link an individual's responses in interview months 1-4 to that individual's responses a year later in interview months 5-8. Critically, there is an eight-month gap between the fourth and fifth observation of each panel. During this gap, we do not have information on the individual's LFS. Nevertheless, we can use the information from the beginning (MIS1-4) and the end of the sample period (MIS5-8) to test the predictions developed from our initial findings. Specifically, we use the four consecutive months from the latter half of the eight-month panels, i.e., MIS5-8, and construct three-month LFS histories of the non-employed in MIS7. We then study transitions from non-employment in MIS7 to employment in MIS8 conditional on the immediate three-month LFS history in MIS5-7 and the LFS history in MIS1-4.

We test two critical empirical predictions implied by our earlier claim. First, consider the nonemployed in MIS7 who were also not employed in MIS6 and MIS5. If the duration since and the

\footnotetext{
${ }^{17}$ Even after excluding these groups, the employment transition rate among those OLF for three consecutive months is still the lowest among all of the 18 LFS histories, 0.037 (Appendix Table A3.1 and Figure A3.6).
} 
instability of the previous employment are negatively correlated with probability of finding a job, then, on average, those individuals who were continuously employed in MIS1-4 should have higher job finding rates than those individuals with no employment in MIS1-4. To test this prediction, we estimate a linear probability model of transitions from non-employment to employment between MIS7 and MIS8 on the set of LFS history dummies in MIS5-8 interacted with histories in MIS1-4. ${ }^{18}$ Figure 3.2, Panel A shows the coefficient estimates for the dummies corresponding to the LFS histories of the non-employed in MIS5-7 conditional on continuous employment in MIS1-4 as well as on non-employment in MIS1-4. Our findings indicate that individuals with continuous employment a year ago have a job finding rate 2-4 times higher than individuals without employment.

Second, consider the non-employed in MIS7 who were employed in MIS6 and MIS5. Their threemonth LFS history (EEU or EEN) signals high labor attachment. We do not know the employment status of these individuals during the eight months between MIS4 and MIS5. However, if the continuity of the previous employment is important, then, on average, individuals who were continuously employed in MIS1-4 should have a higher job finding rate than individuals with noncontinuous or no employment in MIS1-4. Figure 3.2, Panel B shows the coefficient estimates from our linear probability model for the dummies corresponding to EEU and EEN histories conditional on continuous employment in MIS1-4, some employment in MIS1-4, and no employment in MIS1-4. Consistent with our hypothesis, for both EEU and EEN, individuals with continuous employment in the previous year have a higher job finding rate than individuals with some employment, or no employment in the previous year.

\subsection{Robustness}

In this subsection, we conduct robustness checks to address frequent measurement concerns.

\subsubsection{Temporary Layoffs in Unemployment}

First, we examine whether our results on negative dependence of transition rates on duration of joblessness for the unemployed can be accounted for by temporary layoffs. Specifically, Fujita and Moscarini (2017) argue that once recalls by prior employers are taken into account, the exit rate

\footnotetext{
${ }^{18}$ Additional controls include age, gender, education, year and seasonal dummies.
} 
from unemployment does not exhibit negative duration dependence. The CPS data do not have information on actual recalls, and so we use temporary layoff to account for at least a portion of expected recall.

Focusing on the LFS histories ending with unemployment (EEU, UEU, NEU, EUU, and UUU), we further subdivide each of these histories into two groups based on whether the reason for unemployment was a temporary layoff (L) or other (O). Examining those histories which exclude temporary layoffs, we find that all of our documented regularities continue to hold (See Appendix Figure A3.5).

\subsubsection{Waiting for a New Job to Begin}

One potential hypothesis for the high employment transition rate of those OLF (especially those with recent employment) posits that these individuals have already lined a job up and are simply waiting to begin work. We find that this hypothesis is not consistent with the way that the CPS classifies individuals into OLF. Specifically, the CPS asks two different questions that contain information about "waiting for job to begin" and the individuals who answer affirmatively to either are not classified as OLF. First, if "waiting for a new job to begin" is given as the reason for why the individual is employed but absent from work, they are classified as employed. Second, individuals who answer affirmatively might be classified as unemployed. Specifically, individuals who state that they are looking for work and that they are unavailable to start work last week despite an offer are further asked why they are unavailable. Respondents who choose the option "waiting for a new job to begin" are classified as unemployed (The CPS Manual). Therefore,

"waiting for a new job to begin" cannot account for the high employment transition rates observed among the OLF.

\section{Are Unemployment-OLF Cyclers Misclassified?}

We have shown that our LFS histories contain important information about future transition rates from non-employment to employment. In this section, we challenge a practice in the literature that treats frequent changes between unemployment and OLF (nonparticipation) as classification error. 


\subsection{Employment Transition Rates and Wages of Those Consistently Unemployed, Consistently OLF, and Unemployment-OLF Cyclers}

In the widely cited papers, Abowd and Zellner (1985) and Poterba and Summers (1986) compared responses in the CPS 1981 Re-interview Survey with those in the original survey. Both papers noted that many respondents who were classified as unemployed during the original interview were re-classified as employed or OLF as part of the Re-interview survey. ${ }^{19}$ Both papers employ a methodology of estimating the extent of the classification error by comparing original survey responses with those in the Re-interview survey. Such a methodology implicitly assumes that responses to the Re-interview Survey were error-free. Further complicating this difficulty, the BLS has not conducted a re-interview survey since 1981. In other words, no new data on the issue are available.

The presence of classification error in the data is a concern because the error would induce spurious transitions between labor force states. To resolve these spurious transitions, Elsby, Hobijn, and Sahin (2015) propose a practice known as "DeNUNification," in which the authors treat transition reversals between unemployment and OLF as classification error. Specifically, the NUN labor force status histories are recoded into NNN and UNU into UUU. The authors show that this method substantially reduces estimated transitions in and out of the labor force and reduces the countercyclicality of the transition rate between OLF and unemployment.

The "DeNUNification" correction is rooted in the hypothesis that reversals between unemployment and nonparticipation represent spurious transitions between labor statuses. An alternative hypothesis posits that the reversals are genuine and that respondents reporting UNU or NUN differ in how attached they are to the labor market as compared to those reporting UUU or NNN, respectively. These two contrasting hypotheses can easily be tested by comparing the job finding rates of those OLF with histories NUN and NNN and of the unemployed with histories UNU and UUU.

\footnotetext{
${ }^{19}$ During the Re-Interview Survey, a subset of the original sample was contacted in the week following their initial CPS interview and re-surveyed regarding their labor market-related activities in the initial reference week.
} 
The left-hand side of Panel A in Figure 4.1 shows the monthly employment transition rates of individuals with histories NUN and NNN. The right-hand side shows the respective population shares. Individuals with NUN histories are five times more likely to transition to employment than individuals with NNN histories (0.10 versus 0.02 , Table 3.1), even after controlling for demographics (Table 3.3) or for self-reported desire for work (Figure 6.1). ${ }^{20}$ Consequently, the non-employed with NUN histories exhibit greater attachment to the labor market than the nonemployed with NNN histories. While both appear less attached than those with UUU histories (transition rates of 0.10 versus 0.15 , respectively, Table 3.1), these individuals clearly have not completely left the labor force.

The left-hand side of Panel B in Figure 4.1 presents the employment transition rates of individuals with UNU and UUU histories. The transition rate of individuals with UUU histories is somewhat larger than the comparable rate for UNU individuals; however, the difference is only statistically significant in a few years. ${ }^{21}$ This result supports the notion that for the purposes of accounting for transitions between non-employment and employment, these histories are similar.

However, we find that those individuals with UUU histories who find employment have higher wages than individuals who find employment after cycling between unemployment and OLF (i.e., those with histories UNU, NNU, or NUU). Said result holds even after controlling for demographics (Table 4.1). In other words, an unemployed individual who continuously reports actively searching potentially signals a higher reservation wage than an unemployed individual who cycles between unemployment and OLF.

\subsection{Discussion}

\footnotetext{
${ }^{20}$ In addition, the employment transition rate of individuals with NUN histories is much more cyclically volatile and declines more than the rate of individuals with NNN histories in recessions. The right-hand side of Panel A in Figure 4.1 demonstrates the prevalence of individuals with NUN and NNN histories in the working age population. Over the period from 1976 to 2016, those individuals with NNN histories account for $31 \%$ of the working-age population, on average. The individuals with NNN also constitute almost $90 \%$ of all OLF, i.e., movements in the aggregate labor force participation rate are largely accounted for by changes in the prevalence of this group. For instance, the U-shape of the population share of the NNN individuals inversely tracks the increase and the post-2000 decline of the aggregate labor force participation rate. The population share of NNN individuals exhibits a clear trend and lacks any cyclical patterns. By contrast, the population share of NUN individuals hovers around a quarter percent and displays a clear countercyclical pattern.

${ }^{21}$ The same result holds if we control for age, gender, education, and remove seasonal effects.
} 
Our empirical results regarding the differences in employment transition rates across LFS histories challenge a practice in the literature that treats frequent changes between unemployment and OLF as measurement error. Moreover, these findings have important quantitative implications for the transition probabilities between employment, unemployment and nonparticipation. As mentioned earlier, Elsby et al. (2015) demonstrate that DeNUNification leads to substantially lower transition probabilities. Specifically, under the DeNUNification correction the 2012 transition probability from nonparticipation to unemployment drops by $36 \%$ as compared to the uncorrected data. Similarly, the transition probability from unemployment to nonparticipation drops by $37.5 \%$, and both the 2012 transition probability from employment to nonparticipation and from nonparticipation to employment drop by more than 55\% (see Figure 2, Elsby et al., 2015). By contrast, our results bolster the use of uncorrected transition probabilities and support the conclusion that the U.S. labor market is rather fluid, that there is a lot of churn between labor force statuses, and that frequent switches between LFS contain information about the individual's attachment to the labor market.

We find that the non-employed with NUN histories have an employment transition rate five times higher than individuals with NNN histories. In addition, individuals with UNU and UUU histories have similar employment transition rates but unemployment-nonparticipation cyclers have a lower wage upon reemployment. That is, there are crucial differences in outcomes for individuals with different histories that rule out pure classification error as an explanation for the observed histories. Consequently, NUN and UNU do not appear to be erroneous versions of NNN and UUU, respectively. The data support the interpretation that individuals who frequently change status between OLF and unemployment are more closely attached to the labor market than consistently OLF individuals and less closely attached than consistently unemployed individuals.

\section{A Horse Race: Labor Force Status History versus Detailed Current-Month Information}

In this section, we evaluate whether our LFS histories predict future job finding rates more accurately than the information available in current-month survey responses. For the unemployed, the literature suggests that the most important variables from the current month survey responses are the reported duration of unemployment and the reason of unemployment. For those OLF, the 
most important variables determining labor force attachment are the self-reported desire to work and the reported reasons for not actively searching for work. Therefore, we conduct a horse-race between these current-month responses and the labor force histories as a means of illustrating how accurate our labor force histories are for predicting transitions into employment.

\subsection{Measuring Labor Force Attachment Using Current-Month Information}

The CPS includes a set of questions about search activities, desire to work and other activities of the non-employed. These responses are used to classify the non-employed into the unemployed or those OLF, and also allow researchers to distinguish within those OLF by degree of labor market attachment.

The OLF are asked a series of questions to determine their degree of attachment to the labor market. First, individuals are asked whether they currently want a job. If an individual answers affirmatively, the surveyor then follows up by asking for main reason why the individual did not look for work over the last 4 weeks. Respondents who want a job are also asked about their search activity in the last 12 months. Based on the responses to these follow-ups, the Bureau of Labor Statistics (BLS) assigns to those OLF a label indicating their attachment to the labor market. Individuals who want a job, are available for work, and have looked for a job sometime in the prior 12 months (or since the end of their last job if they held one within the past 12 months), but were not counted as unemployed because they had not searched for work in the 4 weeks preceding the survey are referred to as "marginally attached". Among the marginally attached, the BLS distinguishes between those who gave an economic-related reason for not searching for work (referred to as "Want job, marginally attached, discouraged”), those who gave a non-economicrelated reason for not searching for work (referred to as “Want job, marginally attached, other”), and those who want a job but are neither in the first nor in the second category (referred to "Want job, other”). Finally, the BLS subdivides individuals who do not want a job into the retired, disabled, those in school, and other. In summary, the BLS classifies those OLF into seven groups: (1) want job, marginally attached, discouraged, (2) want job, marginally attached, other, (3) want job, other, (4) do not want job, retired, (5) do not want job, disabled, (6) do not want job, in school (16-24 years old), and (7) do not want job, other. 
We distinguish among the unemployed by self-reported duration and by reason for unemployment (on temporary layoff, on permanent layoff, quit, temporary job ended, new entry, re-entry). We consider ten detailed duration categories: less than 5 weeks, 5-8, 9-14, 15-18, 19-22, 23-26, 27-30, 31-34, 25-28, and 39+ weeks.

\subsection{Horse-Race between the LFS Histories and Current-Month Classification}

In this section, we run a horse race between our three-month LFS histories and the detailed currentmonth classification in order to gauge their ability to explain variation in the non-employed individuals' monthly employment transition rates. Since the detailed current-month classifications for the unemployed and those OLF are mutually exclusive - by duration and reason for the former, and by desire to work and other labor market activities for the latter - we analyze the histories for the unemployed and for those OLF separately, and present pooled results in the appendix.

Table 5.1 presents estimates of a linear probability model of employment transitions for the unemployed. The right-hand side variables of interest are sets of dummy variables representing alternative classifications of the unemployed. The first set represents the nine LFS histories of the unemployed. The other three sets are dummies for each duration category (10 dummies), dummies denting the reason for unemployment (six categories), and dummies for duration-and-reason categories (60 dummies). We also control for age, gender, education, as well as year and month. The sample consists of individuals who were unemployed in month three of our four-month panels provided that we can construct the three-month LFS history and that we can classify by duration and reason for unemployment.

In Columns 1-4 in Table 5.1, we examine specifications that only include either the dummies representing the LFS histories or the dummies representing duration and/or reason of unemployment. Comparing the R-squared across Columns 1-4, we find that the classification by LFS history explains more variation in the employment transition rates of the unemployed than the classification by reported duration or by reason for unemployment (0.093 versus 0.065 and 0.074, respectively). Further, classification by LFS history explains about the same proportion of the variation as does the comprehensive duration-and-reason classification.

Adding an LFS history classification to the duration or reason classifications substantially improves explanatory power. In contrast, adding a duration classification to the LFS history 
classification offers negligible improvement in explaining power; whereas adding the reason for unemployment to the LFS history classification goes a bit further in explaining the variation. Overall, we find that the LFS history classification alone explains as much as of the variation as the classification by duration and reason of the unemployed. However, adding the LFS history to this classification provides additional explanatory power (Column 4 versus Column 7). ${ }^{22}$

We now run a similar horse race for those OLF (Table 5.2). We again use sets of dummies to represent the nine LFS histories of the OLF and a set of seven dummies indicating the desire for work as well as the other labor market attachment groupings described above. Additional controls in the regressions include age, gender, education, dummies for year and for month, and a constant. Column 1 shows the results of a regression with only the LFS history classification dummies, Column 2 shows the results of a regression with the seven current-month categories above, and Column 3 shows the results of a regression with both sets of dummies included. Remarkably, the $\mathrm{R}^{2}$ from the regression on the set of LFS dummies is almost four times larger than the $\mathrm{R}^{2}$ from the regression on the set of current-month dummies (Column 1 versus 2). By contrast, adding the current-month classification to the LFS history classification does not improve the explanatory power (Column 1 versus 3).

These results clearly demonstrate that our LFS histories contain significantly more information about the employment transition propensity of the non-employed than the one-month LFS. ${ }^{23}$ Equally important, the LFS histories contain information beyond what can be extracted from the current-month variables on the duration and reason for unemployment as well as the desire for work and labor-market activities of those OLF. Finally, most of the explanatory power in our results is driven by the LFS histories of those OLF. For these individuals, the LFS histories contain information about the duration since their most recent employment, which is a crucial factor for predicting future employment and which is not extracted from the current-month CPS questions.

\subsection{Detailed Labor Force Status History versus Past Labor Force Statuses}

\footnotetext{
${ }^{22}$ The likelihood ratio test rejects Model in Column 4 in favor of Model in Column 7. Appendix Table A5.3 contains additional robustness results with the continuous duration variable and alternative groupings for reported duration.

${ }^{23}$ The results from the estimated linear probability model of employment transitions on the pooled sample of the unemployed and those OLF are in Appendix Table A5.1.
} 
In Tables 5.1-5.2 we considered how well a model with a full set of dummies for the 18 different LFS-histories leading up to $\mathrm{U}$ or $\mathrm{N}$ performed in predicting employment transition. In this subsection, we consider this model's performance relative to a more parsimonious specification relying on a set of non-interacted indicator variables for LFS in each of the current and past two months. After omitting a base LFS category in each of these three months, this simpler model only requires estimating 5 coefficients as opposed to the full 17 required for the specification that is fully saturated for LFS-histories.

This simpler model restricts the effects of the different LFS statuses in different months to be the same regardless of the statuses in the other months. For example, an individual who is employed and an individual who is OLF in month $t-1$ have the same change in their probability of reemployment regardless of whether said individual is unemployed or OLF in month t. Further, said individuals have the same change in their probability of reemployment regardless of their LFS in month $t-2$.

We find that the R-squared from the two models are similar, but that the likelihood ratio test rejects the parsimonious model in favor of the fully saturated model. ${ }^{24}$ In contrast to the LFS histories model, the parsimonious model does not allow distinguishing between short- and long-duration of the previous employment, which we previously found to be an important factor in transitions to employment.

\section{Duration of Joblessness versus Self-Reported Labor Attachment among those OLF}

In the previous section, we demonstrated that self-reported desire to work and reason for not searching explain little of the variation in employment transition rates among those OLF compared to their LFS histories. In this section, we examine how employment transition rates of those OLF vary conditional on their self-reported labor market attachment and their LFS history. We find that

\footnotetext{
${ }^{24}$ The estimates from the model with full 18 LFS histories and the simple model of past labor force statuses are in Appendix Table A5.2. In the parsimonious model, the largest positive coefficient is on the dummy denoting employment in period $\mathrm{t}-1$, the second largest coefficient is on the dummy denoting employment in period t-2, and finally the third largest coefficient is on the dummy denoting unemployment in period $\mathrm{t}$. That is, first, duration since the most recent employment is the most powerful predictor of employment in the future. Second, unemployment versus OLF predicts a higher employment transition rate.
} 
recent employment is a much more powerful predictor of future employment than self-reported labor market attachment.

Figure 6.1 presents estimates from a linear probability model of the individual OLF-toemployment transition rate on the full set of interactions for the seven self-reported labor market attachment dummies with the nine LFS histories dummies (colored lines). For comparison, the figure also shows the estimates from the model with the seven self-reported labor market attachment dummies alone (black line).

The figure shows that there are substantial differences in the transition rates between histories with recent continuous employment (the top line), histories with some recent employment (the four lines in the middle), and histories with no recent employment (the bottom four lines). By contrast, there is no clear pattern across self-reported labor market attachment once we condition on the LFS history. The average OLF individual who reports wanting a job has a much lower job finding rate than the average OLF individual who was recently employed, regardless of her self-reported desire to work. In particular, those OLF who were employed in the past two months (i.e., EEN) but who also report not wanting a job or being retired or disabled, transition to employment at a higher rate than those OLF who want a job but have no recent employment.

Examining the composition of those OLF by self-reported labor market attachment and LFS history, we find that the majority of those wanting a job have no recent employment and, therefore, low employment transition rates. ${ }^{25}$ Those OLF with recent employment are most likely to report not wanting a job or being in school or retired.

\section{Duration of Joblessness versus Reported Duration of Unemployment}

The CPS surveys the unemployed regarding the length of time that they have been searching for work. Standard research practice commonly relies on the responses to these questions to measure how long respondents have been unemployed. The BLS also provides estimates of the stock of long-term unemployed based on these responses. In this section, we ask what these self-reported

${ }^{25}$ These results are shown in Appendix Table A6.1. 
durations of unemployment actually measure by examining how they are related to our LFS histories.

We conclude that the standard approach to interpreting the respondents' reported durations in the CPS is flawed for several reason. First, many unemployed report long durations even though we observe them employed or OLF in the previous period. Such responses are not consistent with the underlying assumptions of measuring unemployment durations using these self-reports.

Second, we show that job finding rates decline with duration of joblessness conditional on the selfreported duration of unemployment. The converse is not true: job finding rates do not decline with self-reported durations once the duration of joblessness is accounted for. Further, we find that reported durations of 5+ weeks are more common after short-term employment or on-the-job search (or, more precisely “working while searching” to signify searching as a primary activity). In this context, it is interesting to note that the actual survey question asks the unemployed how long they have been "looking for work," not how long they have been unemployed. Therefore, the reported durations are consistent with respondents including on-the-job search while possibly omitting temporary, stop-gap employment when they answer this question. In other words, the error is not in how respondents answer questions, but rather in the way analysts have interpreted their answers.

Finally, based on our results, we construct a new distribution of joblessness for the unemployed that combines the observed duration of joblessness for individuals in the CPS panel transitioning from employment to unemployment with the reported duration of unemployment for the rest of the unemployed. A distribution constructed in this way has higher mass on shorter durations than the distribution of reported durations typically used in the literature.

\subsection{Reported Duration of Unemployment and Previous Labor Force Status}

To understand what is reported as duration of unemployment, it is essential to review the original survey question that the CPS uses to collect the information that eventually is reported as duration of unemployment. This question is posed to the unemployed, who are defined as the non-employed who are available and actively searching for work during the reference week. This group is asked how long they were looking for work, not for how long they satisfied all the necessary criteria to be counted as unemployed. In other words, the question does not explicitly concern the duration 
of unemployment. Nevertheless, this reported duration is typically treated by the literature as the duration of unemployment and referred to as such.

Table 7.1, Panel A shows the distribution of the unemployed in month $t$ 's reported duration of unemployment conditional on their labor force status in month $t$-1 (for 1976-2016 and 1994-2016). If the reported duration is consistent with an unemployed individual's past labor force status, the unemployed whose labor force status in the previous month is employment or OLF should report unemployment duration of less than 5 weeks. However, we find that during 1976-2016, on average, $20 \%$ of the unemployed who were employed in the previous month report duration of 5 weeks or longer and approximately 4\% report durations longer than 26 weeks. Among the unemployed who were OLF in the previous month, approximately $50 \%$ reports duration of unemployment of 5 weeks or longer with approximately 13\% reporting durations longer than 26 weeks. $^{26}$

An alternative way to see the discrepancy between the reported duration and the previous month's labor force status is to examine the distribution of the previous month's status based on the unemployed individual's reported duration of unemployment (Table 7.1, Panel B). During the period of 1976-2016, among the unemployed who reported durations of unemployment of 5-26 weeks, on average, $8.6 \%$ were employed last month and $16.6 \%$ were OLF. Among the unemployed with reported durations 27-52 weeks, 4.9\% were employed last month and 13.5\% were OLF.

\subsection{Joblessness Durations, Reported Duration of Unemployment, and Subsequent Employment Transition Rates}

In this subsection, we examine how reported unemployment durations and observed joblessness durations interact in predicting transitions to employment. We will argue that the duration of

\footnotetext{
${ }^{26}$ The percentage of these seemingly inconsistent reports varies systematically over time (Appendix Figure A7.1). The share of such reports appears to be countercyclical, i.e., increasing during recessions and declining during recoveries. After 2007, reports of durations 53 weeks or longer increased substantially among the newly unemployed, reaching $5 \%$ of all new transitions from employment and $25 \%$ of all new transitions from OLF. The cyclical behavior for reports of long (5-26 weeks) versus very long (53 weeks or longer) durations also differs. This difference is especially striking after the 2007-09 recession. While the reports of duration of 5-26 weeks declined rapidly to the pre-recession level in 2011, the reports of duration of 53+ weeks continued to grow reaching their peak in 2012.
} 
joblessness and the reported duration of unemployment (or, more precisely, looking for job) are economically distinct measures and capture different labor market states.

In Section 5, we showed that self-reported durations and observed joblessness durations explain similar fractions of the variation in employment transition rates of the unemployed. However, this does not imply that they represent the same phenomenon. Table 7.2 captures why the two classifications explain a similar fraction of the variation in employment transition rates. This table shows the transition rates for the unemployed grouped in three alternative ways: by reported duration, by their LFS in the previous month and by the interaction of the reported duration and the LFS in the previous month. The table also includes the share of each group among the entire unemployed population. On average, the job finding rate among those reporting a duration of less than 5 weeks and those reporting employment in the previous month are roughly comparable ( 0.35 and 0.44 respectively). These high-transition rate groups are also roughly the same size, making up $34 \%$ and $23 \%$ of unemployment, respectively. However, most of the unemployed either have longer reported durations or were unemployed/OLF in the preceding month. Each of these groups of unemployed have comparable job finding rates of approximately 0.20 . Therefore, the fraction of the variation in the job finding rate that can be explained by using either the reported durations or the actual LFS histories is roughly comparable.

However, the group reporting short durations is not the same as the group that were recently employed. Moreover, it turns out that observed joblessness explains job finding rates even after conditioning on reported unemployment, while the converse is not true. Figure 7.1 displays the estimated unemployment-to-employment transition rate profile by reported duration for all unemployed and three profiles by reported duration of the unemployed conditional on their previous-month labor force status (i.e., those unemployed who were employed in the previous month, those who were unemployed in the previous month, and those who were OLF in the previous month). Table 7.3 contains the estimates of a linear probability model for the individual employment transition rate on the set of dummy variables that represent interactions between the six reported duration categories ( $<5,5-8,9-14,15-26,27-52$ and 53+ weeks) and previous-month's labor force status (employed, unemployed, OLF) with controls for age, gender, education, annual and seasonal dummies. The regressions are estimated separately for the 1976-2016 and for the 1994-2016 periods. 
First, conditional on employment in the previous month, there is almost no negative dependence of the unemployment-to-employment exit rate on the reported duration. Specifically, conditional on being employed last month, the average employment transition rate of the unemployed with reported duration under 5 weeks is 0.45 , of the unemployed with reported duration of $15-26$ weeks - 0.42, and of the unemployed with the reported durations of 27-52 weeks - 0.40 during the period of 1994-2016.

Second, we find economically and statistically significant negative dependence for the reported duration of the unemployment-to-employment exit rates of those who were unemployed or OLF in the previous month. That is, while the reported duration is only a weak predictor of transitions into employment for those recently employed, it is an important factor for individuals who were unemployed or OLF in the previous month.

For those OLF in the previous month, during 1994-2016 the average employment transition rate for the unemployed with reported duration under 5 weeks is 0.23 , for the unemployed with reported duration of 15-26 weeks - 0.15, and of the unemployed with the reported durations of 27-52 weeks - 0.12 (Table 7.2). For the unemployed with longer reported durations, the employment transition rate is similar whether they were unemployed or OLF in the previous month, especially in the period from 1994 to 2016. Additionally, we find that the unemployed who were OLF last month and reported short unemployment durations have job finding rates closer to those of the short-term unemployed. This similarity may stem from these unemployed just starting their job search. By contrast, the unemployed who were OLF last month and reported longer durations may have been searching for longer as their job finding rates are much lower.

Third, the most striking differences in the employment transition rates of the unemployed are not revealed by reported duration but by employment versus non-employment in the previous month. Specifically, we find substantially larger employment transition rates among those who were recently employed regardless of their reported duration. In this sense, observed joblessness is a more important predictor of future employment than the reported unemployment duration.

Figure 7.1 therefore shows that the negative duration dependence profile of the aggregate unemployment-to-employment transition rate (gray line) is a combination of the following three phenomena. First, a high transition rate of the unemployed who were recently employed, who 
constitute $60 \%$ of all reporting durations less than 5 weeks. Second, a much lower transition rate of recently unemployed or OLF, who constitute more than $90 \%$ of those reporting $5+$ weeks. Finally, negative duration dependence of transition rate for those reporting $5+$ weeks who were recently unemployed or OLF.

\subsection{Short-Term Employment and Working while Searching}

As shown above, the duration of actual joblessness constructed from the LFS histories is a more significant predictor of the employment transition rate than the reported duration of unemployment. In this subsection, we focus on the unemployed who were employed last month and report unemployment durations of 5 weeks or longer. We show that such reports do not reflect a reporting error; instead, they contain important information on the type of labor market activity and the type of jobs that these individuals were engaged in prior to unemployment.

First, we find that individuals employed for less than one month prior to becoming unemployed are more likely to report long durations of unemployment (5+ weeks) than individuals whose previous jobs lasted longer. This is not an error. Rather, respondents see the short-term jobs as part of a job search spell. These short employment spells tend to reset the negative dependence of the job finding rate on reported duration. Second, for some of the new transitions from employment to unemployment, the reported longer duration of unemployment indicates that the individuals started on-the-job search during the preceding spell of employment. In such cases, the individuals who transitioned from employment to unemployment and report durations of 5+ weeks of looking for work have higher employment transition rates than individuals who reported starting looking for a job upon entering unemployment. Finally, the incidence of longer reported durations for new employment to unemployment transitions is countercyclical.

\subsubsection{Not a Reporting Error}

Consider the case of an unemployed individual who was employed last month and whose selfreported unemployment duration exceeds one month. There are three possible hypotheses explaining the reporting behavior of such respondents. First, the previous labor force status might have been reported erroneously so that the individual was in fact unemployed and looking for a job. Second, the current unemployment duration is reported erroneously and the individual's reported unemployment duration should be less than one month. Finally, it is possible that neither 
the previous month's employment nor the current month's unemployment duration was erroneously reported. Instead, the individual was indeed employed last month but was also searching and, thus, accurately reported a long duration.

It is straightforward to use the estimated employment transition rates to reject the first hypothesis. Specifically, the employment transition rate for the unemployed reporting longer durations is much higher if they were employed than if they were non-employed in the previous month (see Table 7.3). Thus, the previous month's employment status for the unemployed who reported long durations is not an error.

Nor do the long reported durations following employment seem erroneous. Rather, being employed and looking for work are not mutually exclusive states. Those who report long durations in the period immediately after employment were often engaged in job search while employed and were simply holding a short-term job while searching for a better alternative. To make the case for this interpretation, we now specifically examine situations when unemployed individuals who were employed last month report long durations of unemployment.

\subsubsection{Short-Term Jobs}

We begin our analysis by examining the duration of prior employment spells. First, we find that when prior employment spells were short, then newly unemployed are more likely to report long unemployment durations and the average length of reported durations is higher.

Specifically, Table 7.4 shows the average incidence for reported durations of less than 5 weeks, 526 weeks, 27-52 weeks, and 53 weeks or longer, by the length of previous employment. Figure 7.2 shows the time series. ${ }^{27}$ From 1976 to 2016, among the unemployed who were employed in the previous month but non-employed in the two months prior, $40 \%$ report durations of 5 weeks or more. The median of these longer reported durations is 19 weeks (see Appendix Figure A7.2 for the time series of the mean and median). By contrast, among the unemployed who were employed

\footnotetext{
${ }^{27}$ We construct Table 7.4 and Figure 7.2 using the duration information for the unemployed in month four of our four-month panels who were classified as employed in month three. The four-month length of the panel allows distinguishing among the unemployed in month four who were employed in at least three consecutive months prior to unemployment, employed in two consecutive months and non-employed three month ago prior to unemployment, and finally employment one month prior to unemployment and nonemployed two months prior to unemployment.
} 
in the three consecutive months prior, only $15 \%$ report durations of 5 weeks or more. The median of these longer reported durations is 8.5 weeks. However, 55\% of the unemployed reporting durations $5+$ weeks come from the LFS histories with three months of consecutive employment because the fraction of unemployed with at least three month of employment is larger than the fraction with 1-month of employment (72\% versus $14 \%)$.

Second, long durations reported after short-term employment are consistent with the respondent's reported duration of unemployment prior to short-term employment, i.e., the longer reported durations are not arbitrary. Specifically, for individuals who were unemployed just prior to shortterm employment and immediately afterwards (i.e., the LFS history UEU), we can measure the difference between the reported durations prior to and after a short-term employment spell. Among those reporting long durations subsequent to a short-term employment spell, the median difference is 6 weeks, the $25^{\text {th }}$ percentile is 0 , and the $75^{\text {th }}$ percentile is 11 weeks. These results are consistent with some respondents stopping their "clock" during short-term employment when later reporting the number of weeks of searching for work (a discrepancy of 0 ). Moreover, other individuals seem to continue searching through the short-term employment period (a discrepancy of almost two months). These two observations strongly suggest that when the reported unemployment durations are inconsistent with observed employment spells, such observations tend to include short-term employment and prior unemployment spells. Therefore, these individuals are not just reporting an error.

Third, we demonstrate how job finding rates by reported unemployment duration depend on the length of the prior employment spell. Table 7.5 shows the incidence of reported short ( $<5$ weeks) and long (5+ weeks) unemployment durations conditional on the length of prior employment among the new transitions into unemployment. This table reveals two key facts. First, if the prior employment spell lasted longer, then the newly unemployed tend to rapidly transition back into employment. Second, conditional on having held a job lasting at least two months, the job finding rates for the newly unemployed do not vary with self-reported durations. Rather, the average job finding rate for this group is 0.452 if they report a duration shorter than 5 weeks, and 0.472 if their reported unemployment duration is longer than 5 weeks (Table 7.5). Conditional on having held a job that only lasted one month, we do find an effect of reported durations on job finding rates, but 
this effect is small. ${ }^{28}$ This suggests that the unemployed who start looking for a job while still employed have at least as high or higher employment transition rates than the unemployed who started looking for a job after they separated from their employer.

Finally, the incidence of longer reported durations for the unemployed who were employed last month is countercyclical (Figure 7.2). This result is consistent with the emerging evidence that onthe-job search is countercyclical and might be driven by precautionary motives (Ahn and Shao, 2017).

\subsection{Duration Distribution Corrected for Observed Joblessness and Implications}

The duration distribution commonly used in the literature is based on self-reported durations. Besides this distribution, we can also construct duration distributions based on the observed LFS histories. These distributions differ from each other because self-reported and observed unemployment durations often disagree, as we have shown in Section 7.1.

We now construct a corrected duration distribution based on our finding from Section 7.2 that employment spells reset the job finding rate irrespective of self-reported duration while OLF spells do not. That is, the unemployed who were employed in the previous month and who reported durations of 5+ weeks of looking for work have employment transition rate similar to those who reported short durations of unemployment. This similarity does not hold if an unemployed individual who was OLF in the previous month reports a longer duration. Using this information, we construct a novel distribution of unemployment durations that employs the observed duration of joblessness in the LFS histories, instead of the reported durations.

Specifically, we start with the duration distribution for the unemployed in month four of the CPS panels and we prioritize observed durations of non-employment if we observe an instance of employment in the panel. The four-month panels permit us to extend the distribution across four observed duration bins: (1) less than 5 weeks ( $\left.U_{4}\right)$, (2) 5-8 weeks ( $\left.U_{5.8}\right)$, (3) 9-14 weeks (U9.14), and (4) 15 weeks or longer $\left(\mathrm{U}_{15+}\right)$. If an unemployed individual was employed in the previous month, we assign that individual a duration of less than 5 weeks. If an unemployed individual was non-employed in the previous month and employed two months ago, we use his reported duration

${ }^{28}$ For this group, the employment transition rate is 0.40 conditional on reporting a duration of less than 5 weeks and 0.355 conditional on reporting a duration longer than 5 weeks. 
but topcode it to 8 weeks. If an unemployed individual was non-employed in the previous two months and employed three months ago, we use his reported duration but topcode it to 14 weeks. If an unemployed individual was non-employed in the previous three months, we use his reported duration. We refer to this distribution as the "distribution of joblessness of the unemployed."

For comparison, we construct two other kinds of distributions: (1) the conventional distribution of reported durations based on self-reported durations (i.e., ignoring the observed LFS histories); and (2) the distribution of actual unemployment from the LFS histories (i.e., in which either observed OLF or employment break the duration of unemployment).

Our preferred distribution, the distribution of joblessness, has a higher mass at shorter durations than the distribution of reported durations does (Table 7.6) (as anticipated from the results in Section 7.1). Under this distribution, from 1976 to 2016, 39\% of the unemployed were out of employment for less than 5 weeks, on average. However, only 34\% of the unemployed reported a jobless spell of less than 5 weeks. In the distribution of observed unemployment from the LFS, this share jumps to $46 \%$.

Figure 7.3 shows the duration distributions over time. The distribution of reported durations (black line) increasingly gathers mass at longer durations of unemployment. In contrast, the distribution of observed unemployment from the LFS histories (red line) is relatively stable over time. The discrepancy between these two distributions comes from the observation that after the 2007-09 recession the unemployed from both employment and OLF progressively report longer durations. ${ }^{2930}$

Our preferred distribution lies between the distribution of reported durations and the distribution of observed unemployment from the LFS histories (the blue line in Figure 7.3). Over time, this distribution loses mass at durations of less than 5 weeks and gathers mass at durations of 15 weeks and longer. In 2010, the share of short-term (less than 5 weeks) unemployment reached its

${ }^{29}$ See Appendix Figure A7.3 that presents the distribution of reported durations for the unemployed individuals who were employment, OLF, or unemployed in the previous month.

${ }^{30}$ A portion of the discrepancy between the reported durations and the LFS histories after 1994 is due to the CPS redesign. In 1994, the CPS switched to a dependent interviewing wherein the duration for an unemployed individual is increased by one month if that individual was also unemployed in the previous month. That is, if the individual remains unemployed, any initially reported longer duration is carried over to the next month. 
minimum of $20 \%$ under the corrected distribution and of $15 \%$ under the distribution of reported durations. In 2010, the share of long-term (15 weeks and longer) unemployment reached its maximum of $55 \%$ under the corrected distribution and of $65 \%$ under the distribution of reported durations.

The distribution of the duration of unemployment has important implications for the analysis of the inflows and outflows of unemployment. For example, the share of short-term unemployment plays a key role in the construction of the job finding rate proposed by Shimer (2012). Shimer shows that the number of unemployed workers at date $t+1$ is equal to the number of unemployed workers at date $t$ who do not find a job (fraction $1-F_{t}$, where $F_{t}$ is the job finding rate) plus $u s_{t+1}$ short-term unemployed workers (i.e., those who are unemployed at date $t+1$ but held a job at some point during period $t$ ). Inverting this expression, Shimer derives a convenient formula for the job finding rate, $F_{t}=1-\left(u_{t+1}-u s_{t+1}\right) / u_{t}$ (see Eq. 4, Shimer, 2012). ${ }^{31}$ We use this formula to calculate the job finding rate by employing two different measures of the short-term unemployed - a conventional measure of short-term unemployment (reporting less than 5 weeks) from the reported durations and our proposed measure of short-term unemployment which includes a correction for observed joblessness. Our proposed duration distribution has a higher mass at shorter durations. That is, it implies a higher job finding rate than the self-reported duration distribution. We find that the average job finding rate from 1994 to 2016 is 0.31 under this duration distribution corrected for observed employment, while the average job finding rate is 0.26 under the conventional self-reported duration of unemployment (see Appendix Figure A7.4).

\section{Conclusion}

We propose a novel approach to studying factors correlated with transitions from non-employment to employment using individual's LFS history constructed from the publicly available panels of the CPS data.

Using this novel approach, we characterize new important factors that are associated with higher transitions to employment that cannot be extracted from current-month information. Specifically,

31 This formula describes the job finding rate in a world with two labor market statuses (employment and unemployment). 
among the OLF, we find that information on recent employment from the LFS history explains four times more variation in the employment transition rate than the respondents' reported desire and reason for not looking for work. Not only the duration since an individual's most recent employment but also the duration of an individual's recent employment matters. For the unemployed, we are able to combine the information on the reported duration of unemployment with our observed duration of joblessness to study an individual's employment transition rates and their incidence of short-term employment. Finally, based on our findings, we construct a distribution of unemployment durations that corrects the reported durations using the observed employment in our LFS histories. The resulting distribution has a larger mass at short durations and smaller mass at longer durations, as compared to the distribution of reported durations typically used in the literature.

This paper leaves a great deal for future work. One promising direction lies in making a distinction between ex ante heterogeneity and causal effects derived from the behavior of the non-employed on the employment transition probability. Another direction for future research concerns the measurement of full potential employment and resource utilization in the labor market. We have begun this work in Horsntein, Kudlyak and Lange (2014).

\section{References}

Abowd, John M., and Arnold Zellner. 1985. "Estimating Gross Labor-Force Flows," Journal of Business and Economic Statistics, Vol. 3 (3): 254-283.

Ahn, Hie Joo, and James D. Hamilton. 2014. "Heterogeneity and Unemployment Dynamics," University of San Diego, mimeo. Accessed at http://econweb.ucsd.edu/ jhamilto/AH1.pdf.

Ahn, Hie Joo, and Ling Shao. 2017. "Precautionary On-the-Job Search over the Business Cycle,” mimeo. Accessed at https://sites.google.com/site/hiejooahn/research.

Alvarez, Fernando, Katarina Borovickova, and Robert Shimer. 2017. “Decomposing Duration Dependence in a Stopping Time Model,” mimeo.

Blanchard, Olivier, and Peter Diamond. 1990. "The Cyclical Behavior of the Gross Flows of U.S. Workers,” Brookings Papers on Economic Activity, Vol. 2: 85-155. 
Clark, Kim B. and Lawrence H. Summers. 1979. "Labor Market Dynamics and Unemployment: A Reconsideration," Brookings Papers on Economic Activity, Vol. 1: 13-72.

Coles, Melvyn G., and Eric Smith. 1998. “Marketplaces and Matching,” International Economic Review, Vol. 39: 239-255.

Current Population Survey Interviewing Manual 2013. U.S. Department of the Census.

Diamond, Peter. 2013. “Cyclical Unemployment, Structural Unemployment,” IMF Economic Review, Vol. 61: 410-455.

Elsby, Michael W. L., Bart Hobijn, and Aysegul Sahin. 2015. "On the Importance of the Participation Margin for Labor Market Fluctuations," Journal of monetary Economics, Vol. 72: 64-82.

Elsby, Michael W. L., Bart Hobijn, Aysegul Sahin, and Rob Valletta. 2012. "The Labor Market in the Great Recession: an Update to September 2011," Brookings Papers on Economic Activity 103:353-371.

Elsby, Michael W. L., Ryan Michaels, and Gary Solon. 2009. "The Ins and Outs of Cyclical Unemployment," AEJ: Macro, Vol. 1 (1): 84-110.

Fallick, Bruce C., and Charles A. Fleischman. 2004. "Employer-to-Employer Flows in the U.S. Labor Market: the Complete Picture of Gross Worker Flows,” FEDS Working Paper No.2004-34.

Farber, Henry S., and Rob Valletta. 2015. “Do Extended Unemployment Benefits Lengthen Unemployment Spells?” Journal of Human Resources, Vol. 50(4): 873-909.

Feng, Shuaizhang, and Yingyao Hu. 2013. "Misclassification Errors and the Underestimation of the US Unemployment Rate,” American Economic Review, Vol. 103(2): 1054-70.

Flinn, Christopher J., and Heckman, James J.. 1983. "Are Unemployment and Out of the Labor Force Behaviorally Distinct Labor Force States?" Journal of Labor Economics, Vol. 1(1): 28-42.

Fujita, Shigeru, and Garey Ramey. 2009. “The Cyclicality of Separation and Job Finding Rates,” International Economic Review, Vol. 50(2): 415-430. 
Fujita, Shigeru, and Giuseppe Moscarini. 2017. “Recall and Unemployment,” American Economic Review, Vol. 107(12): 3875-3916.

Hall, Robert E.. 1970. “Why Is the Unemployment Rate So High at Full Employment?” Brookings Papers on Economic Activity, Vol. 3: 369-410.

Hall, Robert E.. 1983. “Is Unemployment a Macroeconomic Problem?” American Economic Review Papers and Proceedings, 1983, Vol. 73 (2): 219-22.

Hall, Robert E.. 2005. "Employment Fluctuations with Equilibrium Wage Stickiness,” American Economic review, Vol. 95 (1): 50-65.

Hall, Robert E., and Sam Schulhofer-Wohl. 2017. "Measuring Job-Finding Rates and Matching Efficiency with Heterogeneous Jobseekers,” American Economic Journal: Macroeconomics, Vol. 10(1): 1-32.

Hornstein, Andreas. 2012. “Accounting for Unemployment: The Long and Short of It,” Federal Reserve Bank of Richmond Working Paper No. 12-07.

Hornstein, Andreas, Marianna Kudlyak, and Fabian Lange. 2014. Measuring Resource Utilization in the Labor Market. FRB Richmond, Economic Quarterly, Q1 2014.

Jones, Stephen R. G., and W. Craig Riddell. 2006. "Unemployment and Nonemployment: Heterogeneities in Labor Market States," Review of Economics and Statistics, Vol. 88(2): 314-23.

Jones, Stephen R. G., and W. Craig Riddell. 1999. "The Measurement of Unemployment: An Empirical Approach," Econometrica, Vol. 67(1): 147-162.

Kroft, Kory, Fabian Lange, Matthew J. Notowidigdo and Lawrence F. Katz. 2016. "Long-Term Unemployment and the Great Recession: The Role of Composition, Duration Dependence and Non-Participation,” Journal of Labor Economics, Vol. 34 (S1, Part 2): S7-S54.

Krueger, Alan B., Judd Cramer and David Cho. 2014. "Are the Long-Term Unemployed on the Margins of the Labor Market?” BPEA, Spring.

Krusell, Per, Toshihiko Mukoyama, Richard Rogerson, and Ayşegül Şahin. 2012. "Is Labor Supply Important for Business Cycles?" NBER Working Papers 17779. 
Kudlyak, Marianna, and Felipe Schwartzman. 2012 “Accounting for Unemployment in the Great Recession: Nonparticipation Matters,” Working Paper 12(4) (Federal Reserve Bank of Richmond). Madrian, Brigitte C., and Lars John Lefgren. 1999. “A Note on Longitudinally Matching Current Population Survey (CPS) Respondents,” NBER Working Paper No. t0247.

Nekarda, Christopher J.. 2009. "A Longitudinal Analysis of the Current Population Survey: Assessing the Cyclical Bias of Geographic Mobility," mimeo. Accessed at https://chrisnekarda.com/papers/lpd-geomob_20090527.pdf

Nickell, Stephen. 1979. "Estimating the Probability of Leaving Unemployment,” Econometrica, Vol. 47(5): 1249-66.

Polivka, Anne E., and Jennifer M. Rothgeb. 1993. “Overhauling the Current Population Survey: Redesigning the CPS Questionnaire.” Monthly Labor Review, Vol. 116(10): 10-28.

Poterba, James M., and Lawrence H. Summers. 1986. "Reporting Errors and Labor Market Dynamics," Econometrica, Vol. 54(6): 1319-38.

Rothstein, Jesse. 2011. "Unemployment Insurance and Job Search in the Great Recession," Brookings Papers on Economic Activity, Fall: 143-210.

Shimer, Robert. 2012. "Reassessing the Ins and Outs of Unemployment," Review of Economic Dynamics 15, 127-148.

Veracierto, Marcelo. 2011. "Worker Flows and Matching Efficiency,” Federal Reserve Bank of Chicago Economic Perspectives Vol. 35 4th Quarter: 147-169.

Van Zandweghe, Willem. 2017. "The Changing Cyclicality of Labor Force Participation," Economic Review, Q3: 1-30. 
Table 3.1: Employment Transition Rates and Population Shares, by Labor Force Status History

\begin{tabular}{lrrrr}
\hline \hline & \multicolumn{2}{c}{$\begin{array}{c}\text { Employment transition } \\
\text { rate }\end{array}$} & \multicolumn{2}{c}{ Population share } \\
\hline LFS History & $1976-2016$ & $1994-2016$ & $1976-2016$ & $1994-2016$ \\
\hline EEU & 0.46 & 0.46 & $0.63 \%$ & $0.59 \%$ \\
EEN & 0.40 & 0.39 & $1.15 \%$ & $1.11 \%$ \\
UEU & 0.39 & 0.39 & $0.12 \%$ & $0.11 \%$ \\
NEU & 0.37 & 0.37 & $0.05 \%$ & $0.05 \%$ \\
EUU & 0.30 & 0.30 & $0.37 \%$ & $0.33 \%$ \\
ENU & 0.30 & 0.30 & $0.12 \%$ & $0.11 \%$ \\
UEN & 0.28 & 0.29 & $0.07 \%$ & $0.07 \%$ \\
NEN & 0.25 & 0.24 & $0.41 \%$ & $0.38 \%$ \\
EUN & 0.24 & 0.25 & $0.12 \%$ & $0.12 \%$ \\
NNU & 0.18 & 0.16 & $0.48 \%$ & $0.47 \%$ \\
UUU & 0.17 & 0.17 & $1.36 \%$ & $1.29 \%$ \\
ENN & 0.17 & 0.17 & $1.19 \%$ & $1.15 \%$ \\
NUU & 0.17 & 0.15 & $0.35 \%$ & $0.35 \%$ \\
UNU & 0.15 & 0.15 & $0.24 \%$ & $0.24 \%$ \\
UUN & 0.11 & 0.11 & $0.35 \%$ & $0.35 \%$ \\
NUN & 0.10 & 0.10 & $0.34 \%$ & $0.35 \%$ \\
UNN & 0.08 & 0.08 & $0.59 \%$ & $0.58 \%$ \\
NNN & 0.02 & 0.02 & $31.12 \%$ & $30.65 \%$ \\
\hline \hline
\end{tabular}

Note: The sample consists of the four-month CPS panels, restricted to the panels with non-employment (unemployment or OLF) in month three. The tables shows the sample mean of annual averages of monthly (discrete) rates and shares. "E" in the histories denotes employment, "U" - unemployment, and "N" - OLF. All calculations use the CPS sampling weights as described in the text. The histories are ranked by the average employment transition rate over 1976-2016 as tabulated in the first column. 
Table 3.2: Employment Transition Rates: Duration since and Duration of the Recent Employment

\begin{tabular}{|c|c|c|c|c|c|c|}
\hline & Unemployed & OLF & $\mathrm{U}+\mathrm{OLF}$ & Unemployed & OLF & $\mathrm{U}+\mathrm{OLF}$ \\
\hline & 1 & 2 & 3 & 4 & 5 & 6 \\
\hline \multicolumn{7}{|l|}{$\begin{array}{l}\text { Indicators for the most } \\
\text { recent employment: }\end{array}$} \\
\hline Employment in t-1 & $\begin{array}{c}0.403 * * * \\
(0.00637)\end{array}$ & $\begin{array}{c}0.344^{* * *} \\
(0.00103)\end{array}$ & $\begin{array}{l}0.370 * * * \\
(0.00110)\end{array}$ & $\mathrm{x}$ & $\mathrm{x}$ & $\mathrm{x}$ \\
\hline $\mathrm{E}$ in $\mathrm{t}-1, \mathrm{E}$ in $\mathrm{t}-2$ & $\mathrm{X}$ & $\mathrm{x}$ & $\mathrm{x}$ & $\begin{array}{l}0.419 * * * \\
(0.00644)\end{array}$ & $\begin{array}{c}0.385 * * * \\
(0.00110)\end{array}$ & $\begin{array}{l}0.405^{* * *} \\
(0.00115)\end{array}$ \\
\hline $\mathrm{E}$ in $\mathrm{t}-1$, non- $\mathrm{E}$ in $\mathrm{t}-2$ & $\mathrm{x}$ & $\mathrm{x}$ & $\mathrm{x}$ & $\begin{array}{l}0.341^{* * *} \\
(0.00746)\end{array}$ & $\begin{array}{c}0.240 * * * \\
(0.00141)\end{array}$ & $\begin{array}{l}0.272 * * * \\
(0.00148)\end{array}$ \\
\hline Employment in $\mathrm{t}-2$ & $\begin{array}{c}0.257 * * * \\
(0.00656)\end{array}$ & $\begin{array}{c}0.171^{* * *} \\
(0.00107)\end{array}$ & $\begin{array}{c}0.198 * * * \\
(0.00116)\end{array}$ & $\begin{array}{l}0.256 * * * \\
(0.00656)\end{array}$ & $\begin{array}{c}0.171^{* * *} \\
(0.00107)\end{array}$ & $\begin{array}{l}0.198 * * * \\
(0.00115)\end{array}$ \\
\hline No employment in $\mathrm{t}-1, \mathrm{t}-2$ & $\begin{array}{c}0.123 * * * \\
(0.00616)\end{array}$ & $\begin{array}{c}0.0289 * * * \\
(0.000844)\end{array}$ & $\begin{array}{c}0.0415 * * * \\
(0.000945)\end{array}$ & $\begin{array}{l}0.122 * * * \\
(0.00615)\end{array}$ & $\begin{array}{c}0.0288 * * * \\
(0.000842)\end{array}$ & $\begin{array}{c}0.0412 * * * \\
(0.000943)\end{array}$ \\
\hline $\begin{array}{l}\text { Age, gender, educ, year, } \\
\text { seasonls }\end{array}$ & yes & yes & yes & yes & yes & yes \\
\hline Observations & 191,738 & $1,996,728$ & $2,188,466$ & 191,738 & $1,996,728$ & $2,188,466$ \\
\hline F-stat/p-value & 1782 & 9526 & 12370 & 1752 & 9627 & 12369 \\
\hline Adjusted R-squared & 0.299 & 0.180 & 0.206 & 0.300 & 0.185 & 0.210 \\
\hline
\end{tabular}

Note: Table contains estimates from a linear probability model of non-employment to employment transitions. Columns 1-3 show the results from a model with three dummies that indicate the duration since the most recent employment - an indicator for the most recent employment in month t-1, an indicator for the most recent employment in month $\mathrm{t}-2$, and an indicator for no employment in month $\mathrm{t}-1$ and $\mathrm{t}-2$. Columns 4-6 shows the results from an employment linear probability model with four dummies that represent the nature of the previous employment captured by the LFS histories - an indicator for employment in month t-1 and t-2 (i.e., most recent and continuous employment), an indicator for employment in t-1 only, an indicator for employment in t-2 only, and an indicator for no employment in neither t-1 nor t-2. Essentially, we disentangle the first dummy in columns 1-3 into two separate dummies: one representing at least two months of employment and the other representing only 1 month of employment. Additional controls are age, gender, education, year and seasonal dummies. The omitted category for demographics is 35-44 year old females with a high school education. The sample consists of the four-month CPS panels, restricted to the panels with non-employment in month three, 1994-2016. Standard errors are in parentheses. The estimation employs the CPS sampling weights. 
Table 3.3: Employment Transition Rates of the Unemployed and OLF, Conditional on Prior TwoMonth Labor Force Status

\begin{tabular}{|c|c|}
\hline & All non-employed in $\mathrm{t}$ \\
\hline \multicolumn{2}{|l|}{ Indicators for LFS(t-2)LFS(t-1) } \\
\hline \multirow[t]{2}{*}{ EE } & $0.383^{* * *}$ \\
\hline & $(0.00125)$ \\
\hline \multirow[t]{2}{*}{ UE } & $0.272 * * *$ \\
\hline & $(0.00354)$ \\
\hline \multirow[t]{2}{*}{ EU } & $0.237 * * *$ \\
\hline & $(0.00271)$ \\
\hline \multirow[t]{2}{*}{ NE } & $0.231 * * *$ \\
\hline & $(0.00171)$ \\
\hline \multirow[t]{2}{*}{ EN } & $0.161 * * *$ \\
\hline & $(0.00124)$ \\
\hline \multirow[t]{2}{*}{ UU } & $0.0956 * * *$ \\
\hline & $(0.00175)$ \\
\hline \multirow[t]{2}{*}{ NU } & $0.0819 * * *$ \\
\hline & $(0.00176)$ \\
\hline \multirow[t]{2}{*}{ UN } & $0.0698 * * *$ \\
\hline & $(0.00148)$ \\
\hline \multirow[t]{2}{*}{ NN } & $0.0234^{* * *}$ \\
\hline & $(0.000937)$ \\
\hline \multicolumn{2}{|c|}{ Indicators for interactions of LFS(t-2)LFS(t-1) and $\mathrm{U}(\mathrm{t})$} \\
\hline \multirow[t]{2}{*}{ EEU } & $0.0646^{* * *}$ \\
\hline & $(0.00143)$ \\
\hline \multirow[t]{2}{*}{ UEU } & $0.101 * * *$ \\
\hline & $(0.00438)$ \\
\hline \multirow[t]{2}{*}{ EUU } & $0.0449 * * *$ \\
\hline & $(0.00299)$ \\
\hline \multirow[t]{2}{*}{ NEU } & $0.124^{* * *}$ \\
\hline & $(0.00412)$ \\
\hline \multirow[t]{2}{*}{ ENU } & $0.121^{* * *}$ \\
\hline & $(0.00278)$ \\
\hline \multirow[t]{2}{*}{ UUU } & $0.0473^{* * *}$ \\
\hline & $(0.00168)$ \\
\hline \multirow[t]{2}{*}{ NUU } & $0.0532 * * *$ \\
\hline & $(0.00211)$ \\
\hline \multirow[t]{2}{*}{ UNU } & $0.0572 * * *$ \\
\hline & $(0.00214)$ \\
\hline \multirow[t]{2}{*}{ NNU } & $0.127 * * *$ \\
\hline & $(0.00131)$ \\
\hline Age, gender, education, year, seasonls & yes \\
\hline Observations & $2,188,466$ \\
\hline Adjusted R-squared & 0.227 \\
\hline $\mathrm{F}$ & 10541 \\
\hline
\end{tabular}

Note: The table shows the estimates from a linear probability model of individual transitions from non-employment to employment. The sample consists of the four-month CPS panels, restricted to the panels with non-employment (unemployment or OLF) in month three, 1994-2016. The regression does not include constant. The omitted category for demographics is 35-44 year old females with a high school education. Standard errors are in parentheses. The estimation employs the CPS sampling weights. 
Table 4.1: Real Wages of Newly Employed Workers, by LFS History

\begin{tabular}{|c|c|}
\hline UUU & omitted \\
\hline EEU & $\begin{array}{c}0.0689 * * * \\
(0.00684)\end{array}$ \\
\hline UEU & $\begin{array}{l}0.0173 \\
(0.0126)\end{array}$ \\
\hline NEU & $\begin{array}{c}-0.0330^{*} \\
(0.0180)\end{array}$ \\
\hline EUU & $\begin{array}{c}0.0271^{* * *} \\
(0.00905)\end{array}$ \\
\hline ENU & $\begin{array}{c}-0.0484^{* * *} \\
(0.0141)\end{array}$ \\
\hline UNU & $\begin{array}{c}-0.0615^{* * *} \\
(0.0134)\end{array}$ \\
\hline NNU & $\begin{array}{c}-0.0842^{* * *} \\
(0.00941)\end{array}$ \\
\hline NUU & $\begin{array}{c}-0.0808^{* * *} \\
\quad(0.0110)\end{array}$ \\
\hline EEN & $\begin{array}{c}0.0261^{* * *} \\
(0.00682)\end{array}$ \\
\hline UEN & $\begin{array}{c}-0.0547^{* * *} \\
\quad(0.0198)\end{array}$ \\
\hline NEN & $\begin{array}{c}-0.0456 * * * \\
(0.0113)\end{array}$ \\
\hline EUN & $\begin{array}{c}-0.0211 \\
(0.0158)\end{array}$ \\
\hline ENN & $\begin{array}{l}-0.0112 \\
(0.00849)\end{array}$ \\
\hline UNN & $\begin{array}{c}-0.0705^{* * *} \\
(0.0125)\end{array}$ \\
\hline NNN & $\begin{array}{c}-0.0614 * * * \\
(0.00650)\end{array}$ \\
\hline NUN & $\begin{array}{c}-0.0736 * * * \\
(0.0144)\end{array}$ \\
\hline UUN & $\begin{array}{c}-0.0561^{* * *} \\
\quad(0.0133)\end{array}$ \\
\hline $\begin{array}{l}\text { Age, gender, education, } \\
\text { year, seasonals, constant }\end{array}$ & yes \\
\hline Observations & 57,340 \\
\hline Adjusted R-squared & 0.231 \\
\hline r2 & 0.232 \\
\hline $\mathrm{F}$ & 287.61 \\
\hline df_m & 60 \\
\hline
\end{tabular}

Note: The table shows the coefficients estimates from a regression of log real hourly wages of new hires from non-employment with different LFS histories. The sample is restricted to the new hires only. The standard errors are in parentheses. The regression is estimated using the CPS sampling weights. 
Table 5.1: Employment Transition Rate of the Unemployed: Labor Force Status History versus Current-Month Information

\begin{tabular}{|c|c|c|c|c|c|c|c|}
\hline & $\begin{array}{c}\text { LFS } \\
\text { Histories }\end{array}$ & Duration & Reason & $\begin{array}{c}\text { Duration } \\
\text { X } \\
\text { Reason }\end{array}$ & $\begin{array}{c}\text { LFS } \\
\text { Histories } \\
+ \\
\text { Duration }\end{array}$ & $\begin{array}{c}\text { LFS } \\
\text { Histories } \\
+ \\
\text { Reason }\end{array}$ & $\begin{array}{c}\text { LFS } \\
\text { Histories } \\
+ \\
\text { Duration } \\
\text { X } \\
\text { Reason }\end{array}$ \\
\hline & (1) & (2) & (3) & (4) & (5) & (6) & (7) \\
\hline LFS Histoires (9 groups) & yes & $X$ & $X$ & $X$ & yes & yes & yes \\
\hline Duration of Ut (10 gr) & $\mathrm{X}$ & yes & $x$ & $X$ & yes & $\mathrm{X}$ & $\mathrm{X}$ \\
\hline Reason for Ut (6 gr) & $\mathrm{X}$ & $\mathrm{X}$ & yes & $\mathrm{X}$ & $x$ & yes & $\mathrm{X}$ \\
\hline $\begin{array}{l}\text { Duration and Reason for } \\
\text { Ut (10X6 gr) }\end{array}$ & $\mathrm{x}$ & $\mathrm{x}$ & $\mathrm{X}$ & yes & $\mathrm{x}$ & $\mathrm{X}$ & yes \\
\hline $\begin{array}{l}\text { Age, gender, educ, year, } \\
\text { seasonals, cons }\end{array}$ & yes & yes & yes & yes & yes & yes & yes \\
\hline Observations & 191,738 & 191,738 & 191,738 & 191,738 & 191,738 & 191,738 & 191,738 \\
\hline Adjusted R-squared & 0.093 & 0.065 & 0.074 & 0.099 & 0.099 & 0.114 & 0.119 \\
\hline F-stat & 402.4 & 256.4 & 322.3 & 206.4 & 351.7 & 440.9 & 235.7 \\
\hline \multicolumn{8}{|c|}{ LR chi2(8) Model 4 vs Model $7=4340.59$} \\
\hline
\end{tabular}

Note: The sample consists of the four-month CPS panels, restricted to the panels with unemployment in month three, 1994-2016. The regressions are estimated with a constant. When including sets of dummies for LFS histories, duration or reason for unemployment, we omit one category from each classification to avoid multicollinearity. The classification by reported duration of unemployment consists of 10 categories: less than 5 weeks, 5-8, 9-14, 15-18, 19-22, 23-26, 27-30, 31-34, 35-38, and 39+ weeks. The classification by reason for unemployment consist of six categories: temporary layoff, permanent layoff, temporary job ended, quit, re-entry, and new entry. The "Duration and Reason" classification denotes the full set of interactions - 60 dummies, with the base dummy omitted. The demographic controls are a set of two dummies for gender, a set of seven dummies for age, and a set of four dummies for education; we omit one category from each set to avoid multicollinearity. The estimation employs the CPS sampling weights. 
Table 5.2: Employment Transition Rate of those OLF: Labor Force Status History versus CurrentMonth Information

\begin{tabular}{|c|c|c|c|}
\hline & \multicolumn{3}{|c|}{ Classification of the OLF } \\
\hline & LFS Histories & $\begin{array}{l}\text { Current-month } \\
\text { attachment }\end{array}$ & $\begin{array}{c}\text { LFS History + } \\
\text { Current-month } \\
\text { attachment } \\
\end{array}$ \\
\hline & $(1)$ & $(2)$ & $(3)$ \\
\hline LFS Histories (9 groups) & yes & $\mathrm{x}$ & yes \\
\hline $\begin{array}{l}\text { Desire to work, labor for } \\
\text { attachment, retired, in sch } \\
\text { disabled ( } 7 \text { gr) }\end{array}$ & $\mathrm{x}$ & yes & yes \\
\hline $\begin{array}{l}\text { Age, gender, educ, year, } \\
\text { seasonals, cons }\end{array}$ & yes & yes & yes \\
\hline Observations & $1,996,728$ & $1,996,728$ & $1,996,728$ \\
\hline Adjusted R-squared & 0.154 & 0.042 & 0.158 \\
\hline F-stat & 7110 & 1785 & 6551 \\
\hline LR chi2(8) Model2 vs M & 734.74 & & \\
\hline
\end{tabular}

Note: The sample consists of the four-month CPS panels, restricted to the panels with OLF in month three, 1994-2016. The regressions are estimated with a constant. When including sets of dummies for LFS histories or the current-month classification, we omit one category from each classification to avoid multicollinearity. The classification by current-month labor market attachment consists of the seven categories: do not want job - retired, disabled, in school, or other, and want job - discouraged, marginally attached but not discouraged, and other. The demographic controls are a set of 2 dummies for gender, a set of 7 dummies for age, and a set of 4 dummies for education; we omit one category from each set to avoid multicollinearity. The estimation employs the CPS sampling weights. 
Table 7.1: Reported Unemployment Durations and Previous Month's Labor Force Status of the Unemployed

Panel A. Distribution of Reported Unemployment Durations by Previous LFS

\begin{tabular}{crrrrr}
\hline \hline & \multicolumn{5}{c}{ Reported duration in month t, weeks } \\
\cline { 2 - 6 } LFS in month t-1 & $0-4$ & $5-26$ & $27-52$ & $53+$ & Total \\
\cline { 2 - 6 } E & $79.2 \%$ & $17.1 \%$ & $2.0 \%$ & $1.7 \%$ & $100.0 \%$ \\
N & $52.0 \%$ & $34.4 \%$ & $5.8 \%$ & $7.7 \%$ & $100.0 \%$ \\
U & $10.2 \%$ & $62.5 \%$ & $13.7 \%$ & $13.6 \%$ & $100.0 \%$ \\
\cline { 2 - 6 } & \multicolumn{5}{c}{$1994-2016$} \\
E & $80.6 \%$ & $15.1 \%$ & $2.1 \%$ & $2.2 \%$ & $100.0 \%$ \\
N & $45.2 \%$ & $36.8 \%$ & $7.4 \%$ & $10.6 \%$ & $100.0 \%$ \\
U & $3.5 \%$ & $63.2 \%$ & $15.6 \%$ & $17.6 \%$ & $100.0 \%$ \\
\hline \hline
\end{tabular}

Panel B. Distribution of Previous LFS by Reported Unemployment Duration

\begin{tabular}{crrrr}
\hline \hline & \multicolumn{4}{c}{ Reported duration in month t, weeks } \\
\cline { 2 - 5 } LFS in month t-1 & $0-4$ & $5-26$ & $27-52$ & $53+$ \\
\hline & \multicolumn{4}{c}{$1976-2016$} \\
E & $53.3 \%$ & $8.6 \%$ & $4.9 \%$ & $4.2 \%$ \\
$\mathrm{~N}$ & $32.7 \%$ & $16.6 \%$ & $13.5 \%$ & $17.0 \%$ \\
$\mathrm{U}$ & $14.0 \%$ & $74.8 \%$ & $81.6 \%$ & $78.8 \%$ \\
Total & $100.0 \%$ & $100.0 \%$ & $100.0 \%$ & $100.0 \%$ \\
\cline { 2 - 5 } & \multicolumn{4}{c}{$1994-2016$} \\
$\mathrm{E}$ & $61.1 \%$ & $7.3 \%$ & $4.2 \%$ & $3.6 \%$ \\
$\mathrm{~N}$ & $32.9 \%$ & $17.4 \%$ & $14.8 \%$ & $18.1 \%$ \\
$\mathrm{U}$ & $6.0 \%$ & $75.3 \%$ & $81.0 \%$ & $78.3 \%$ \\
Total & $100.0 \%$ & $100.0 \%$ & $100.0 \%$ & $100.0 \%$ \\
\hline \hline
\end{tabular}

Note: The sample consists of the four-month CPS panels restricted to the panels with "Unemployment" in month three. The table displays the sample mean of annual averages. All calculations use the CPS sampling weights. 
Table 7.2: Employment Transition Rates and Shares of the Unemployed by Reported Unemployment Duration and Previous Month Labor Force Status, Averages of Monthly Series

\begin{tabular}{|c|c|c|c|c|c|c|c|c|}
\hline \multirow{2}{*}{$\begin{array}{l}\text { Labor Force } \\
\text { Status in month } \\
\quad \mathrm{t}-1\end{array}$} & \multicolumn{7}{|c|}{ Reported unemployment duration in $\mathrm{t}$} & \multirow[t]{2}{*}{$\begin{array}{c}\text { All } \\
\text { unemployed }\end{array}$} \\
\hline & $\begin{array}{c}<5 \\
\text { weeks }\end{array}$ & $5-8$ & $9-14$ & $15-26$ & $27-52$ & $53+$ & $\begin{array}{l}\mathrm{Al} \mathrm{5+} \\
\text { weeks }\end{array}$ & \\
\hline & \multicolumn{8}{|c|}{ 1976-2016 } \\
\hline \multirow[t]{2}{*}{$\mathrm{E}$} & 0.443 & 0.431 & 0.435 & 0.428 & 0.406 & 0.384 & 0.422 & 0.439 \\
\hline & $17.5 \%$ & $2.0 \%$ & $1.0 \%$ & $0.9 \%$ & $0.7 \%$ & $0.3 \%$ & $5.0 \%$ & $22.5 \%$ \\
\hline \multirow[t]{2}{*}{$\mathrm{U}$} & 0.283 & 0.249 & 0.219 & 0.189 & 0.150 & 0.102 & 0.190 & 0.197 \\
\hline & $5.2 \%$ & $10.5 \%$ & $11.4 \%$ & $11.6 \%$ & $8.5 \%$ & $7.4 \%$ & $49.3 \%$ & $54.6 \%$ \\
\hline \multirow[t]{2}{*}{ OLF } & 0.233 & 0.188 & 0.179 & 0.150 & 0.114 & 0.087 & 0.153 & 0.191 \\
\hline & $11.0 \%$ & $3.3 \%$ & $2.3 \%$ & $2.5 \%$ & $2.4 \%$ & $1.5 \%$ & $12.0 \%$ & $23.0 \%$ \\
\hline \multirow[t]{3}{*}{ All unemployed } & 0.350 & 0.259 & 0.228 & 0.198 & 0.160 & 0.111 & 0.201 & \\
\hline & $33.7 \%$ & $15.7 \%$ & $14.7 \%$ & $15.0 \%$ & $11.6 \%$ & $9.3 \%$ & $66.3 \%$ & $100 \%$ \\
\hline & \multicolumn{8}{|c|}{ 1994-2016 } \\
\hline \multirow[t]{2}{*}{$\mathrm{E}$} & 0.449 & 0.460 & 0.451 & 0.420 & 0.400 & 0.372 & 0.432 & 0.446 \\
\hline & $17.5 \%$ & $1.6 \%$ & $1.0 \%$ & $0.9 \%$ & $0.8 \%$ & $0.4 \%$ & $4.7 \%$ & $22.2 \%$ \\
\hline \multirow[t]{2}{*}{$\mathrm{U}$} & 0.310 & 0.259 & 0.215 & 0.182 & 0.148 & 0.097 & 0.184 & 0.189 \\
\hline & $1.8 \%$ & $9.8 \%$ & $12.2 \%$ & $11.7 \%$ & $9.0 \%$ & $9.7 \%$ & $52.3 \%$ & $54.1 \%$ \\
\hline \multirow[t]{2}{*}{ OLF } & 0.229 & 0.182 & 0.182 & 0.149 & 0.116 & 0.089 & 0.147 & 0.179 \\
\hline & $9.5 \%$ & $3.2 \%$ & $2.5 \%$ & $3.2 \%$ & $3.2 \%$ & $2.1 \%$ & $14.2 \%$ & $23.7 \%$ \\
\hline \multirow[t]{2}{*}{ All unemployed } & 0.368 & 0.264 & 0.225 & 0.188 & 0.156 & 0.106 & 0.193 & \\
\hline & $28.8 \%$ & $14.6 \%$ & $15.6 \%$ & $15.8 \%$ & $13.0 \%$ & $12.2 \%$ & $71.2 \%$ & $100 \%$ \\
\hline
\end{tabular}

Note: Table shows the employment transition rates of the unemployed in month three of our four-month CPS panels. Table also shows the shares (in \%) of the respective groups in the entire pool of the unemployed in month three of our four-month CPS panels. Both the rates and the shares are calculated as the sample mean of the annual averages of monthly series. All calculations use the CPS sampling weights. 
Table 7.3: Employment Transition Rates by Reported Unemployment Duration and Previous Month's Labor Force Status

\begin{tabular}{|c|c|c|}
\hline \multirow{2}{*}{$\begin{array}{l}\text { Reported duration and } \\
\text { previous month LFS }\end{array}$} & (1) & (2) \\
\hline & $1976-2016$ & $1994-2016$ \\
\hline$<5$, employed in $t-1$ & omitted & omitted \\
\hline 5-8, employed in t-1 & $\begin{array}{c}-0.0165 * * * \\
(0.00521)\end{array}$ & $\begin{array}{c}0.0107 \\
(0.00779)\end{array}$ \\
\hline $9-14$, employed in t-1 & $\begin{array}{c}-0.00835 \\
(0.00695)\end{array}$ & $\begin{array}{l}0.00124 \\
(0.00954)\end{array}$ \\
\hline 15-26, employed in t-1 & $\begin{array}{c}-0.0189 * * * \\
(0.00731)\end{array}$ & $\begin{array}{c}-0.0319 * * * \\
(0.01000)\end{array}$ \\
\hline 27-52, employed in t-1 & $\begin{array}{c}-0.0464 * * * \\
(0.00797)\end{array}$ & $\begin{array}{c}-0.0589 * * * \\
(0.0102)\end{array}$ \\
\hline $53+$, employed in $\mathrm{t}-1$ & $\begin{array}{c}-0.0533 * * * \\
(0.0110)\end{array}$ & $\begin{array}{c}-0.0638 * * * \\
(0.0137)\end{array}$ \\
\hline$<5$, unemployed in t-1 & $\begin{array}{c}-0.175 * * * \\
(0.00362)\end{array}$ & $\begin{array}{c}-0.139 * * * \\
(0.00763)\end{array}$ \\
\hline 5-8, unemployed in t-1 & $\begin{array}{c}-0.193 * * * \\
(0.00272)\end{array}$ & $\begin{array}{c}-0.188 * * * \\
(0.00378)\end{array}$ \\
\hline 9-14, unemployed in t-1 & $\begin{array}{c}-0.227 * * * \\
(0.00262)\end{array}$ & $\begin{array}{c}-0.233 * * * \\
(0.00349)\end{array}$ \\
\hline 15-26, unemployed in t-1 & $\begin{array}{c}-0.256 * * * \\
(0.00259)\end{array}$ & $\begin{array}{c}-0.266 * * * \\
(0.00350)\end{array}$ \\
\hline 26-52, unemployed in t-1 & $\begin{array}{c}-0.293 * * * \\
(0.00280)\end{array}$ & $\begin{array}{c}-0.301 * * * \\
(0.00373)\end{array}$ \\
\hline $53+$, unemployed in $\mathrm{t}-1$ & $\begin{array}{c}-0.335^{* * *} \\
(0.00291)\end{array}$ & $\begin{array}{c}-0.343 * * * \\
(0.00363)\end{array}$ \\
\hline$<5$, OLF in $\mathrm{t}-1$ & $\begin{array}{c}-0.203 * * * \\
(0.00276)\end{array}$ & $\begin{array}{c}-0.210 * * * \\
(0.00391)\end{array}$ \\
\hline $5-8$, OLF in $\mathrm{t}-1$ & $\begin{array}{c}-0.251 * * * \\
(0.00421)\end{array}$ & $\begin{array}{c}-0.262 * * * \\
(0.00574)\end{array}$ \\
\hline 9-14, OLF in t-1 & $\begin{array}{c}-0.260 * * * \\
(0.00485)\end{array}$ & $\begin{array}{c}-0.264 * * * \\
(0.00633)\end{array}$ \\
\hline 15-26, OLF in $\mathrm{t}-1$ & $\begin{array}{c}-0.286 * * * \\
(0.00455)\end{array}$ & $\begin{array}{c}-0.292 * * * \\
(0.00566)\end{array}$ \\
\hline 26-52, OLF in $\mathrm{t}-1$ & $\begin{array}{c}-0.322 * * * \\
(0.00453)\end{array}$ & $\begin{array}{c}-0.327 * * * \\
(0.00547)\end{array}$ \\
\hline $53+$, OLF in $t-1$ & $\begin{array}{c}-0.346 * * * \\
(0.00542)\end{array}$ & $\begin{array}{c}-0.352 * * * \\
(0.00645)\end{array}$ \\
\hline $\begin{array}{l}\text { Age, gender, educ, year, } \\
\text { seasonals, cons }\end{array}$ & yes & yes \\
\hline Observations & 362,085 & 191,738 \\
\hline Adjusted R-squared & 0.082 & 0.094 \\
\hline $\mathrm{F}$ & 416.2 & 330.9 \\
\hline
\end{tabular}

Note: The table shows the estimates of a linear probability model of the unemployment-to-employment transition rate. Additional controls are age, gender, education, seasonal and year dummies. The omitted category is 35-44 year old females with a high school education. The estimation uses the CPS sampling weights. 
Table 7.4: Reported Duration of the Newly Unemployed by the Duration of Previous Employment

\begin{tabular}{|c|c|c|c|c|c|c|c|c|}
\hline \multirow[t]{2}{*}{$\begin{array}{l}\text { Previous Labor } \\
\text { Force Status }\end{array}$} & \multirow{2}{*}{$\begin{array}{l}\text { Share in E } \\
\text { to } U \\
\text { transitions }\end{array}$} & \multicolumn{4}{|c|}{$\begin{array}{c}\text { Distribution of reported unemployment } \\
\text { duration in } \mathrm{t}\end{array}$} & \multirow{3}{*}{$\begin{array}{c}\text { Mean } \\
\text { duration, } \\
5+\end{array}$} & \multirow{3}{*}{$\begin{array}{l}\text { Median } \\
\text { duration, } \\
5+\end{array}$} & \multirow{2}{*}{$\begin{array}{c}\text { Share in E to } \\
\text { U transitions } \\
\text { reporting } 5+ \\
\text { weeks }\end{array}$} \\
\hline & & $<5$ & $5-26$ & $27-52$ & $53+$ & & & \\
\hline & \multicolumn{6}{|c|}{ 1976-2016 } & & \\
\hline $\begin{array}{l}\text { Employed in } \mathrm{t}-1, \mathrm{t}-2 \text {, } \\
\mathrm{t}-3\end{array}$ & $72.1 \%$ & $85.5 \%$ & $12.8 \%$ & $0.8 \%$ & $0.8 \%$ & 16.5 & 8.5 & $55.8 \%$ \\
\hline $\begin{array}{l}\text { Employed in } \mathrm{t}-1, \mathrm{t}-2 \text {, } \\
\text { non-employed in } \mathrm{t}-3\end{array}$ & $11.2 \%$ & $77.4 \%$ & $17.7 \%$ & $2.7 \%$ & $2.2 \%$ & 23.7 & 14.0 & $13.5 \%$ \\
\hline \multirow[t]{2}{*}{$\begin{array}{l}\text { Employed in t-1, } \\
\text { non-employed in t-2 }\end{array}$} & $14.3 \%$ & $59.9 \%$ & $28.7 \%$ & $6.3 \%$ & $5.0 \%$ & 27.7 & 19.0 & $30.7 \%$ \\
\hline & \multicolumn{8}{|c|}{ 1994-2016 } \\
\hline $\begin{array}{l}\text { Employed in } \mathrm{t}-1, \mathrm{t}-2 \text {, } \\
\mathrm{t}-3\end{array}$ & $73.3 \%$ & $86.7 \%$ & $11.4 \%$ & $0.9 \%$ & $1.0 \%$ & 18.6 & 9.1 & $52.0 \%$ \\
\hline $\begin{array}{l}\text { Employed in t-1, } \mathrm{t}-2 \text {, } \\
\text { non-employed in } \mathrm{t}-3\end{array}$ & $10.5 \%$ & $78.2 \%$ & $15.8 \%$ & $3.1 \%$ & $2.8 \%$ & 26.9 & 16.4 & $12.2 \%$ \\
\hline $\begin{array}{l}\text { Employed in t-1, } \\
\text { non-employed in t-2 }\end{array}$ & $13.2 \%$ & $61.6 \%$ & $26.2 \%$ & $6.3 \%$ & $5.9 \%$ & 30.6 & 21.4 & $27.1 \%$ \\
\hline
\end{tabular}

Note: The table shows the incidence of the reported durations among the unemployed individuals who were employed in the previous month, by the length of previous employment. The table also shows the mean and median of the longer reported durations ( $5+$ weeks). We use the CPS sampling weights. 
Table 7.5: Employment Transition Rates and Shares of Unemployed by Reported Unemployment Duration and Duration of Previous Employment

\begin{tabular}{|c|c|c|c|}
\hline \multirow[t]{2}{*}{ Previous Labor Force Status } & \multicolumn{3}{|c|}{ Reported unemployment duration in $\mathrm{t}$} \\
\hline & $<5$ weeks & 5+ weeks & All \\
\hline & \multicolumn{3}{|c|}{ 1976-2016 } \\
\hline \multirow[t]{2}{*}{ Employed in $\mathrm{t}-1$ and $\mathrm{t}-2$} & 0.452 & 0.472 & 0.455 \\
\hline & $64.8 \%$ & $13.5 \%$ & $78.3 \%$ \\
\hline \multirow[t]{2}{*}{ Employed in t-1, non-employed in t-2 } & 0.401 & 0.350 & 0.380 \\
\hline & $12.5 \%$ & $9.3 \%$ & $21.7 \%$ \\
\hline \multirow[t]{2}{*}{ All employed in t-1 } & 0.443 & 0.422 & \\
\hline & $77.2 \%$ & $22.8 \%$ & $100.0 \%$ \\
\hline & & 1994-2016 & \\
\hline \multirow[t]{2}{*}{ Employed in $\mathrm{t}-1$ and $\mathrm{t}-2$} & 0.458 & 0.484 & 0.462 \\
\hline & $66.0 \%$ & $13.0 \%$ & $79.0 \%$ \\
\hline \multirow[t]{2}{*}{ Employed in t-1, non-employed in t-2 } & 0.406 & 0.355 & 0.384 \\
\hline & $12.1 \%$ & $8.9 \%$ & $21.0 \%$ \\
\hline \multirow{2}{*}{ All employed in t-1 } & 0.449 & 0.432 & \\
\hline & $78.1 \%$ & $21.9 \%$ & $100.0 \%$ \\
\hline
\end{tabular}

Note: The table shows the employment transition rates and shares (in \%) for the unemployed in month three of our four-month CPS panels who were employed in the previous month. We use the CPS sampling weights. 
Table 7.6: Unemployment Duration Distribution (Reported Durations versus LFS Histories)

\begin{tabular}{lllllll}
\hline \hline & \multicolumn{5}{c}{ Duration of unemployment } \\
& $<5$ & $5-8$ & $9-15$ & $15+$ & Total \\
& weeks & weeks & weeks & weeks & \\
\cline { 2 - 6 } & \multicolumn{5}{c}{$1976-2016$} \\
Reported duration of unemployment & $34.0 \%$ & $15.3 \%$ & $13.1 \%$ & $37.7 \%$ & $100.0 \%$ \\
Reported, corrected for employment in LFS & $39.0 \%$ & $16.3 \%$ & $12.5 \%$ & $32.3 \%$ & $100.0 \%$ \\
Actual unemployment in LFS histories & $46.2 \%$ & $18.8 \%$ & $10.8 \%$ & $24.2 \%$ & $100.0 \%$ \\
\cline { 2 - 6 } & \multicolumn{5}{c}{$1994-2016$} \\
Reported duration of unemployment & $29.1 \%$ & $14.3 \%$ & $13.6 \%$ & $43.0 \%$ & $100.0 \%$ \\
Reported, corrected for employment in LFS & $33.7 \%$ & $15.6 \%$ & $13.1 \%$ & $37.5 \%$ & $100.0 \%$ \\
Actual unemployment in LFS histories & $46.1 \%$ & $18.8 \%$ & $10.9 \%$ & $24.1 \%$ & $100.0 \%$ \\
\hline \hline
\end{tabular}

Note: The table shows the duration distributions of the unemployed in month four of the four-month CPS panels. The reported duration distribution is constructed directly from the reports. The distribution of observed unemployment in the LFS histories is constructed as follows: less than 5 weeks, when the individual is unemployed in month four but employed or OLF in month three; 5-8 weeks, when the individual is unemployed in months four and three but employed or OLF in month two; 9-14 weeks, when the individual is unemployed in months four, three and two but employed or OLF in month one; and, finally, 15 weeks or longer, when the individual is unemployed in all four consecutive months. Our preferred distribution, the distribution of reported durations corrected for previous employment is constructed as follows: if the unemployed was employed in the previous month, we assign duration $<5$ weeks; if the unemployed was either unemployed or OLF in the previous month and employed two months ago, we use his reported duration but topcode it at 5-8 weeks if the reported duration is longer; if the unemployed was either unemployed or OLF in the two previous months and employed three months ago, we use his reported duration but topcode it at 9-14 weeks if the reported duration is longer; if the unemployed for non-employed in the preceding three months, we use his reported duration. We use the CPS sampling weights. 
Figure 3.1: Employment Transition Rates by Labor Force Status History, with and without Demographic Controls

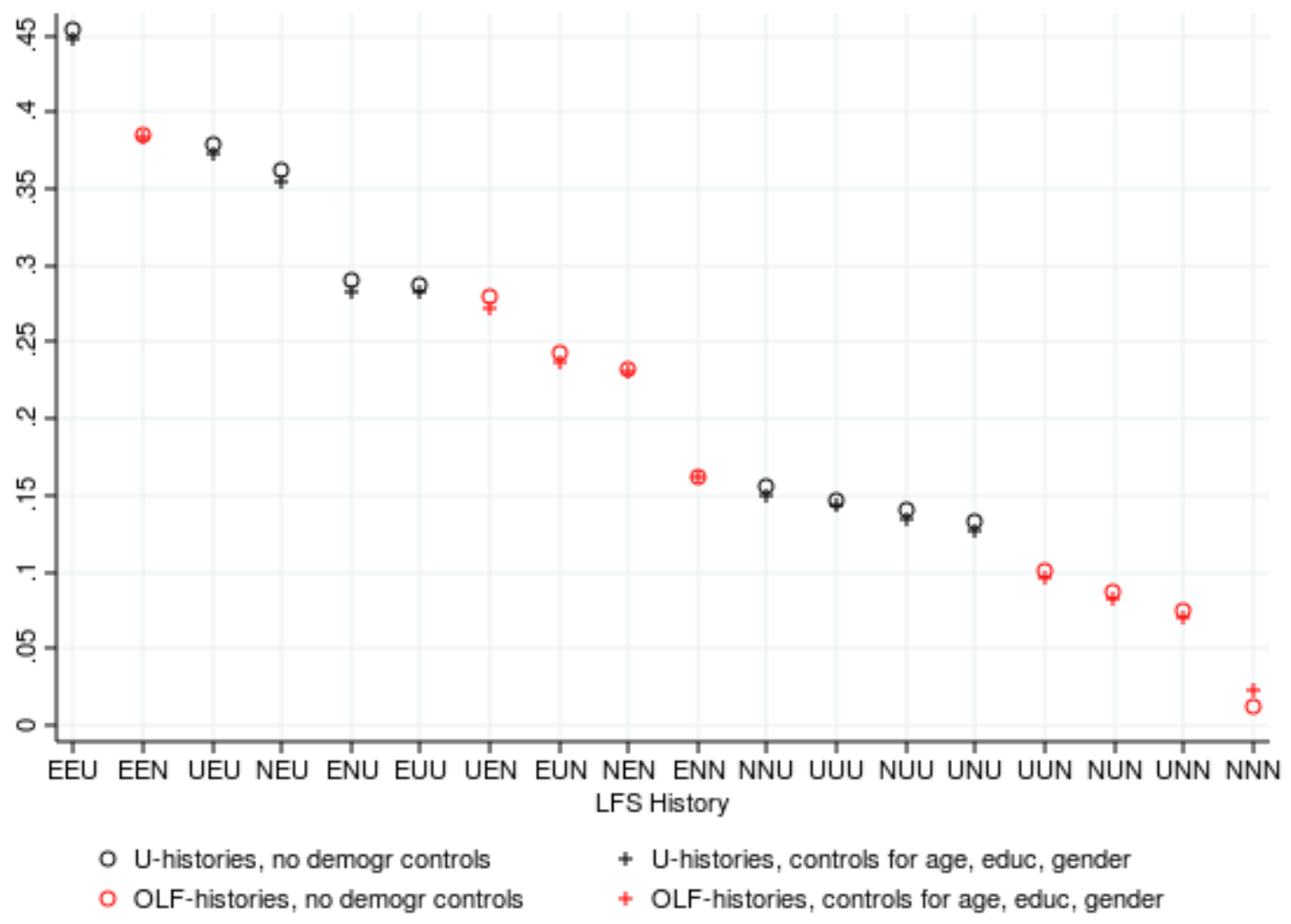

Note: The figure shows estimates from two regressions, 1994-2016. The regression without demographic controls includes annual dummies and seasonal dummies. The regression with demographic controls in addition includes dummies for age, gender and education. The estimation employs the CPS sampling weights. 
Figure 3.2: Duration since and Stability of the Previous Employment, 8-month CPS panels.

Panel A. Employment transition rates of the non-employed in MIS5-7 conditional on LFS history a year ago

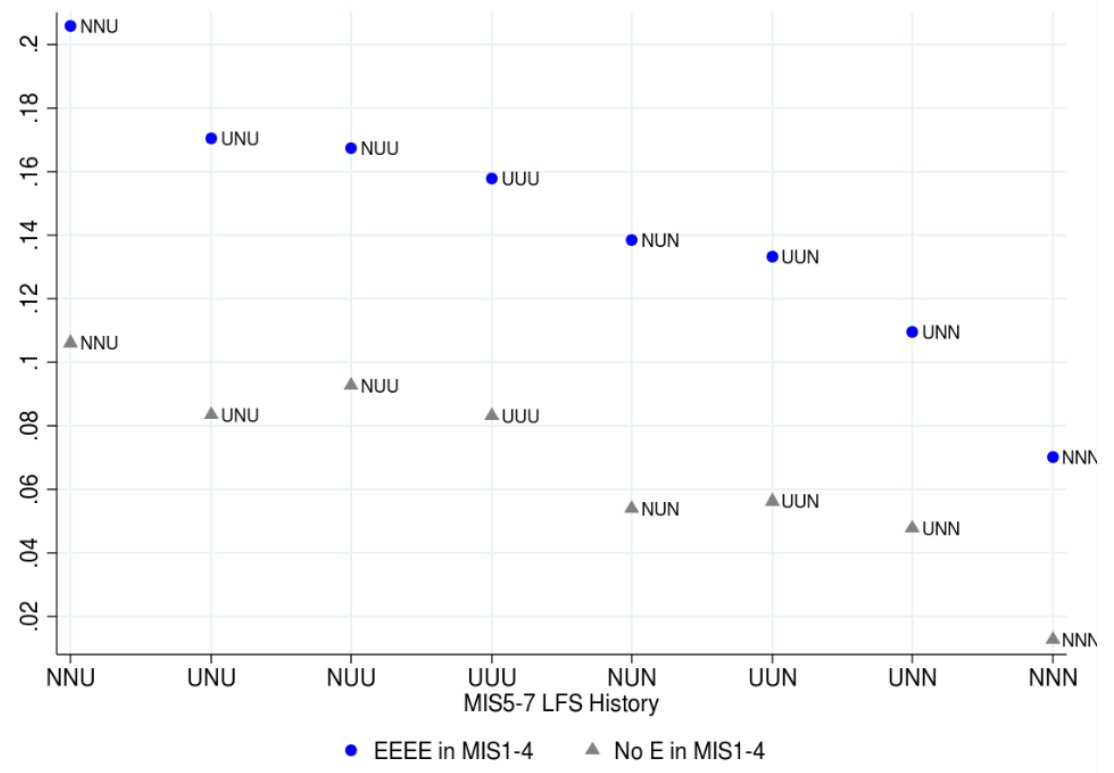

Panel B. Employment transition rates of the non-employed in MIS5-7 conditional on continuous employment in MIS1-4 as well as conditional on no employment in MIS1-4

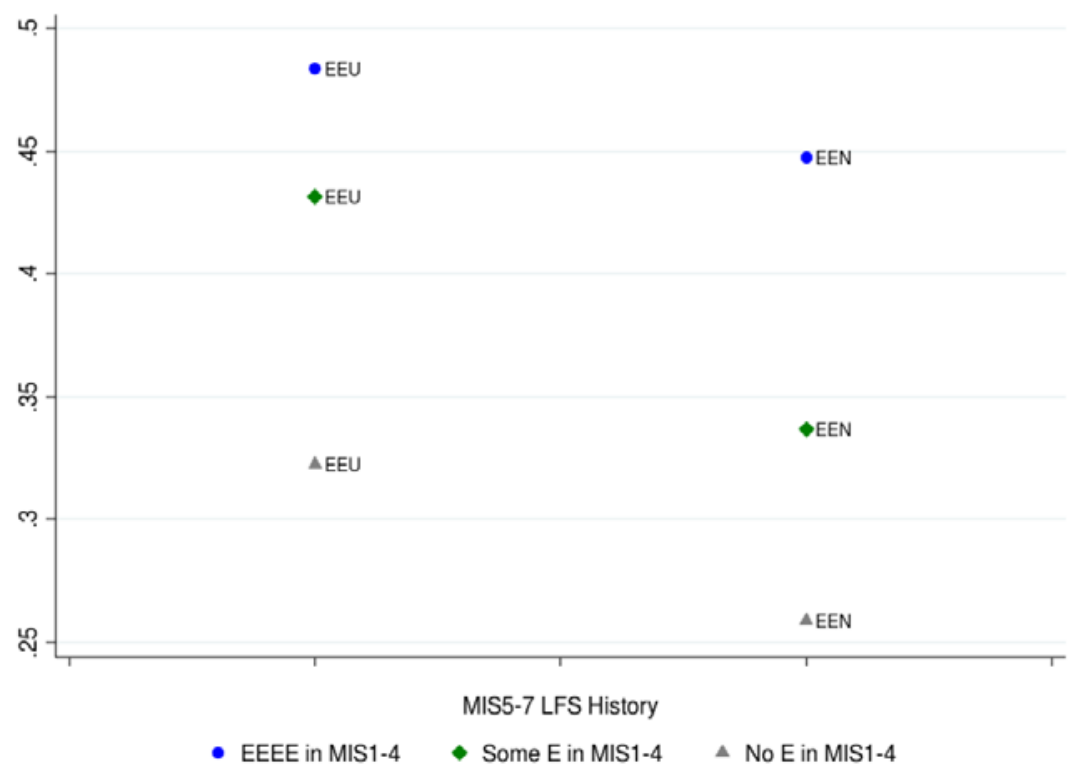

Note: The figure shows the coefficient estimates from two linear probability models of individual unemployment-to-employment transition rate. The regressions are estimated without a constant, additional controls are age, gender, education, seasonal and year dummies (the omitted category is 35-44 year old females with a high school education). 
Figure 4.1: Unemployment-Nonparticipation Cyclers versus Continuously Unemployed or OLF

Panel A. NUN and NNN

Employment Transition Rates

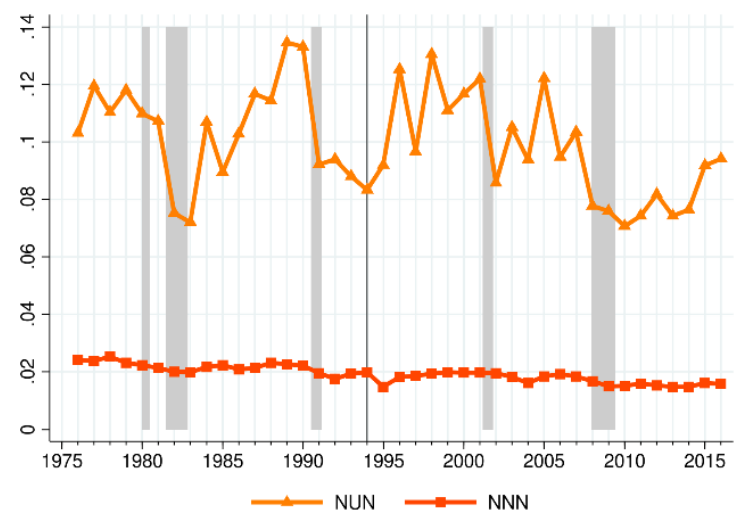

Population Shares

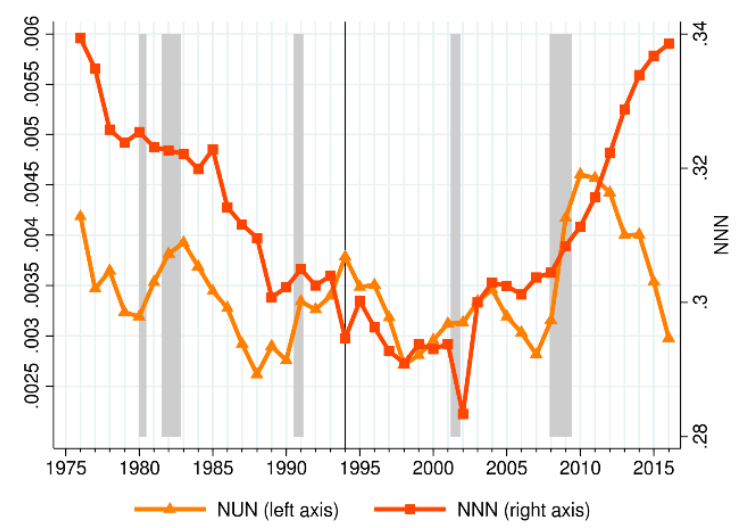

Panel B. UNU and UUU

Employment Transition Rates

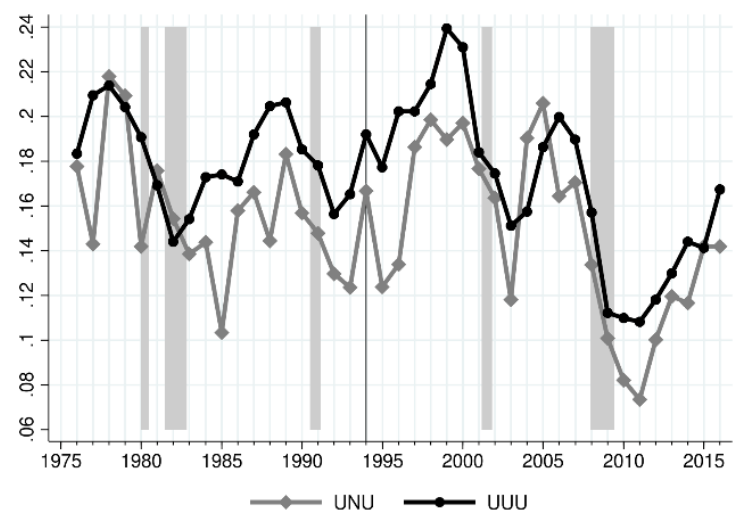

Population Shares

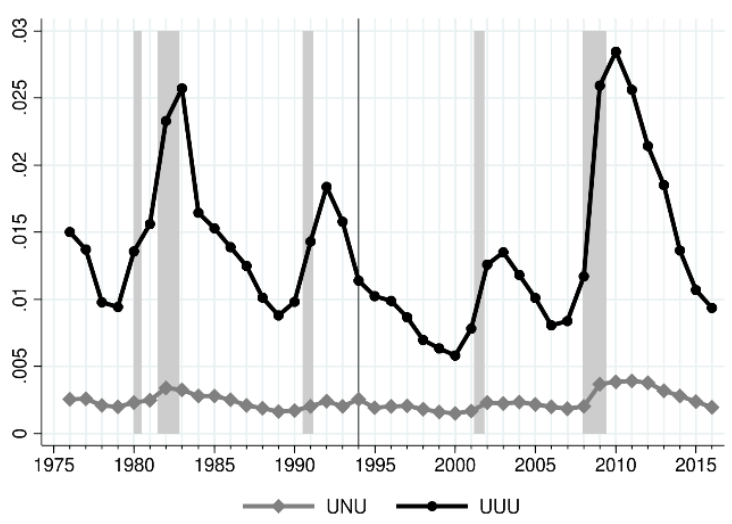

Note: The figure shows annual averages of monthly series. Population shares are the shares in the civilian noninstitutionalized population 16 years old and older. The vertical line shows the 1994 CPS redesign year. All figures are constructed using the CPS sampling weights. 
Figure 6.1: Employment Transition Rates of those OLF by Self-Reported Labor Market Attachment, All OLF, and LFS History

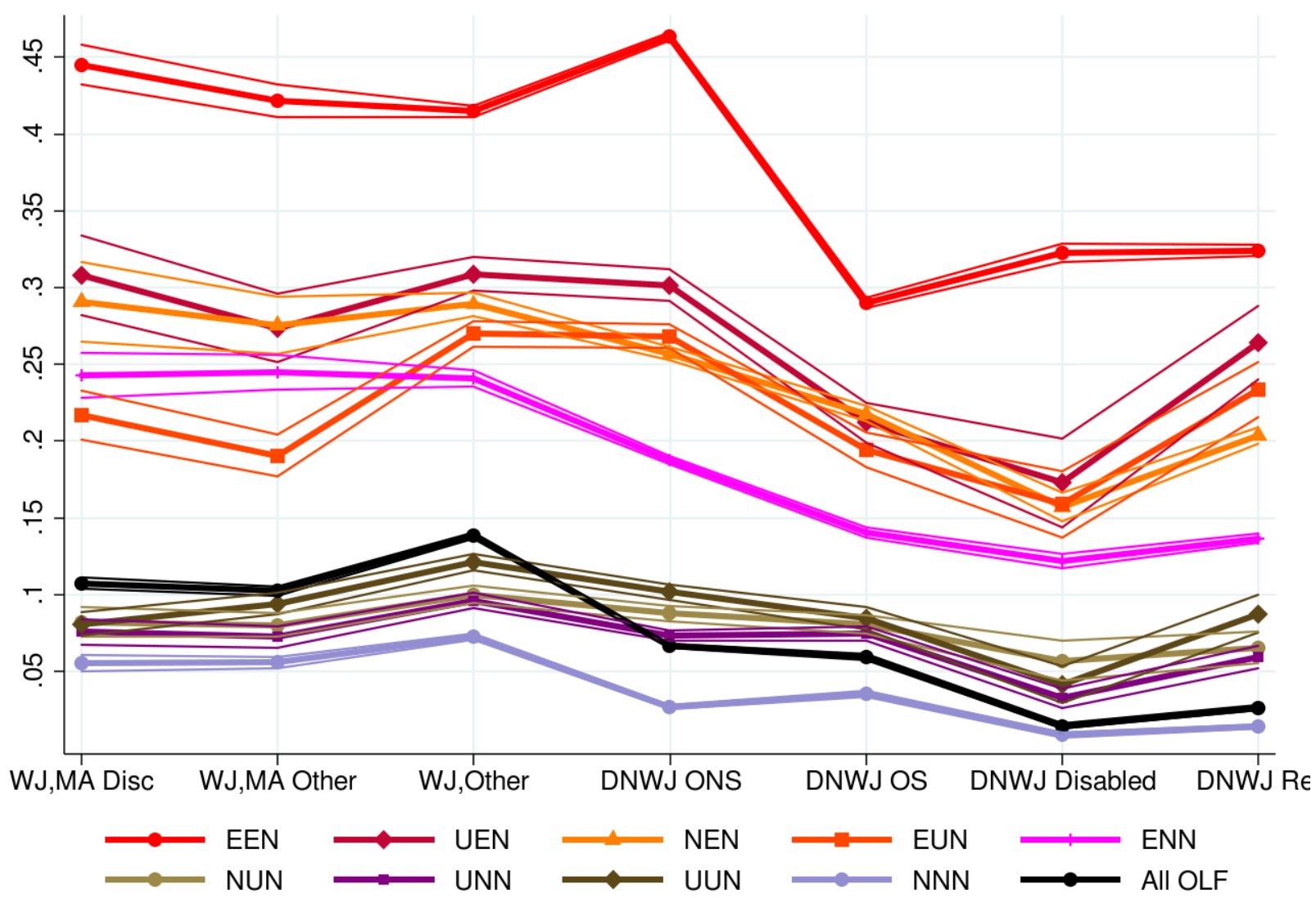

Note: The figure shows the coefficient estimates and 95\% confidence intervals from two linear probability models of the individual OLF-to-employment transition rate. The first model (black line) includes seven dummies representing self-reported labor market attachment: (1) "WJ,MA Disc": want job, marginally attached, discouraged, (2) "WJ,MA Other": want job, marginally attached, other, (3) "WJ,Other”: want job, other, (4) "DNWJ,ONS": do not want job, not retired, not disabled, not in school, (5) "DNWJ,OS":do not want job, in school, 16-24 y. o., (6) "DNWJ,Disabled”: do not want job, disabled, (7) "DNWJ,Retired”: do not want job, retired. The second model includes a full set of interactions of the seven self-reported labor market attachment dummies with nine LFS histories of the OLF (colored lines). The regressions are estimated without a constant, additional controls are age, gender, education, and seasonals (the omitted category is 35-44 year old females with a high school education). The estimates are similar with or without annual controls. The estimation employs the CPS sampling weights. 
Figure 7.1: Unemployment-to-Employment Transition Rate by Reported Duration and Previous Month Labor Force Status

Panel A. 1976-2016

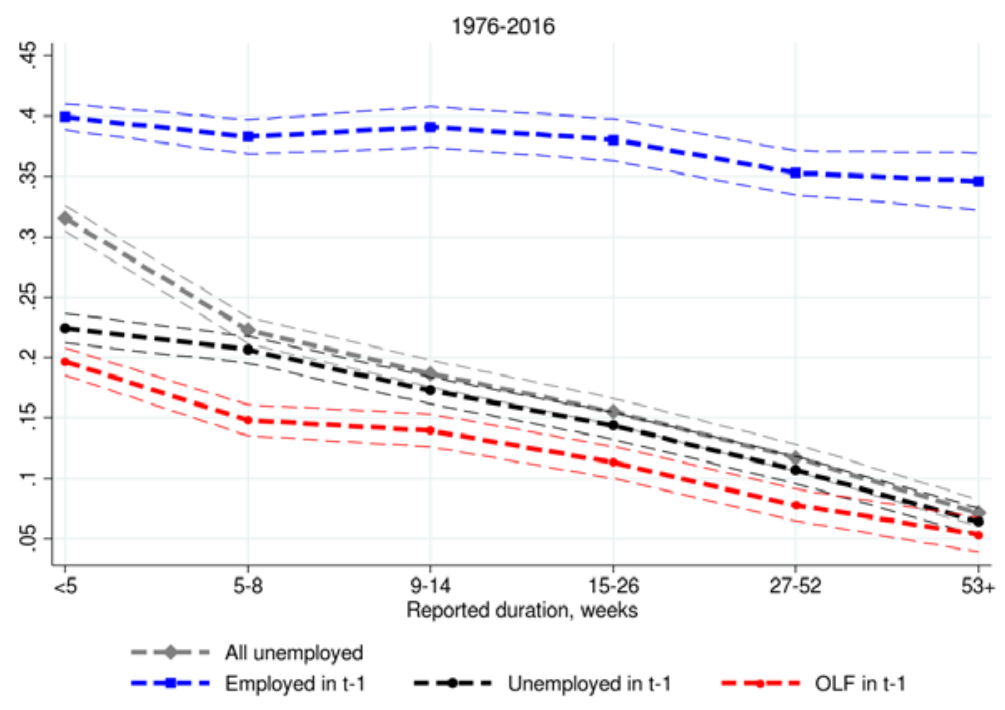

Panel B. 1994-2016

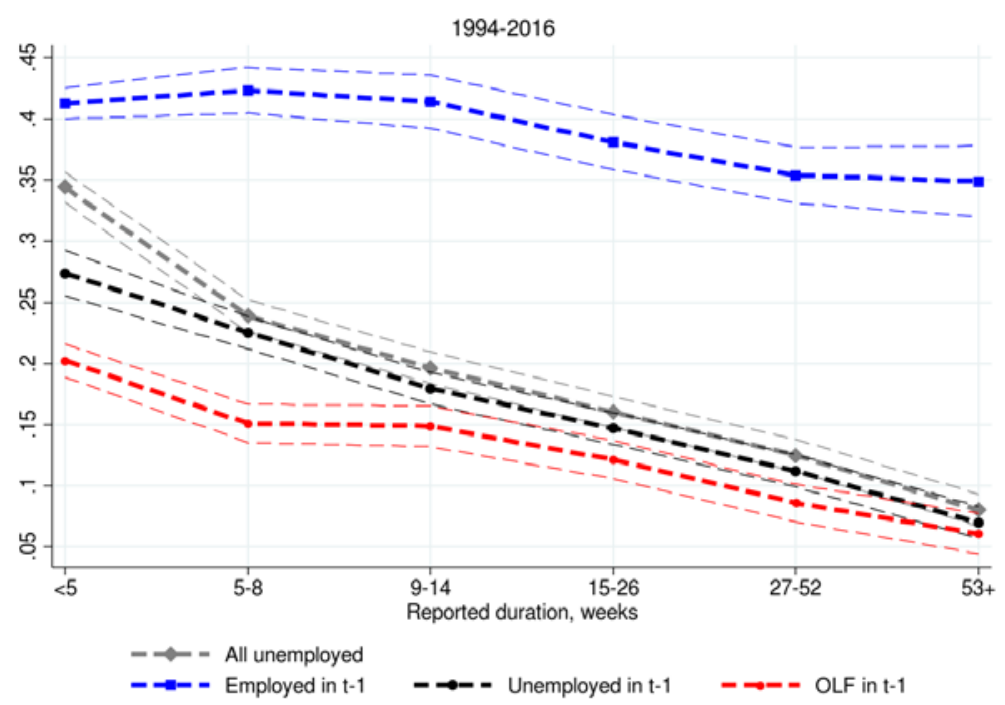

Note: The figure shows the coefficient estimates from two linear probability models of the individual unemployment-to-employment transition rate: (1) a model with six dummies representing reported duration (gray line), (2) a second model with dummies representing interactions of reported duration with the previous month's LFS. The regressions are estimated without a constant. Additional controls are age, gender, education, seasonal and year dummies (the omitted category is 35-44 year old female with high school education). The coefficient estimates and the 95\% CI from the regression in Table 7.3. 
Figure 7.2: Incidence of Reported Durations of 5+ Weeks among New Transitions from Employment to Unemployment, by Length of Previous Employment

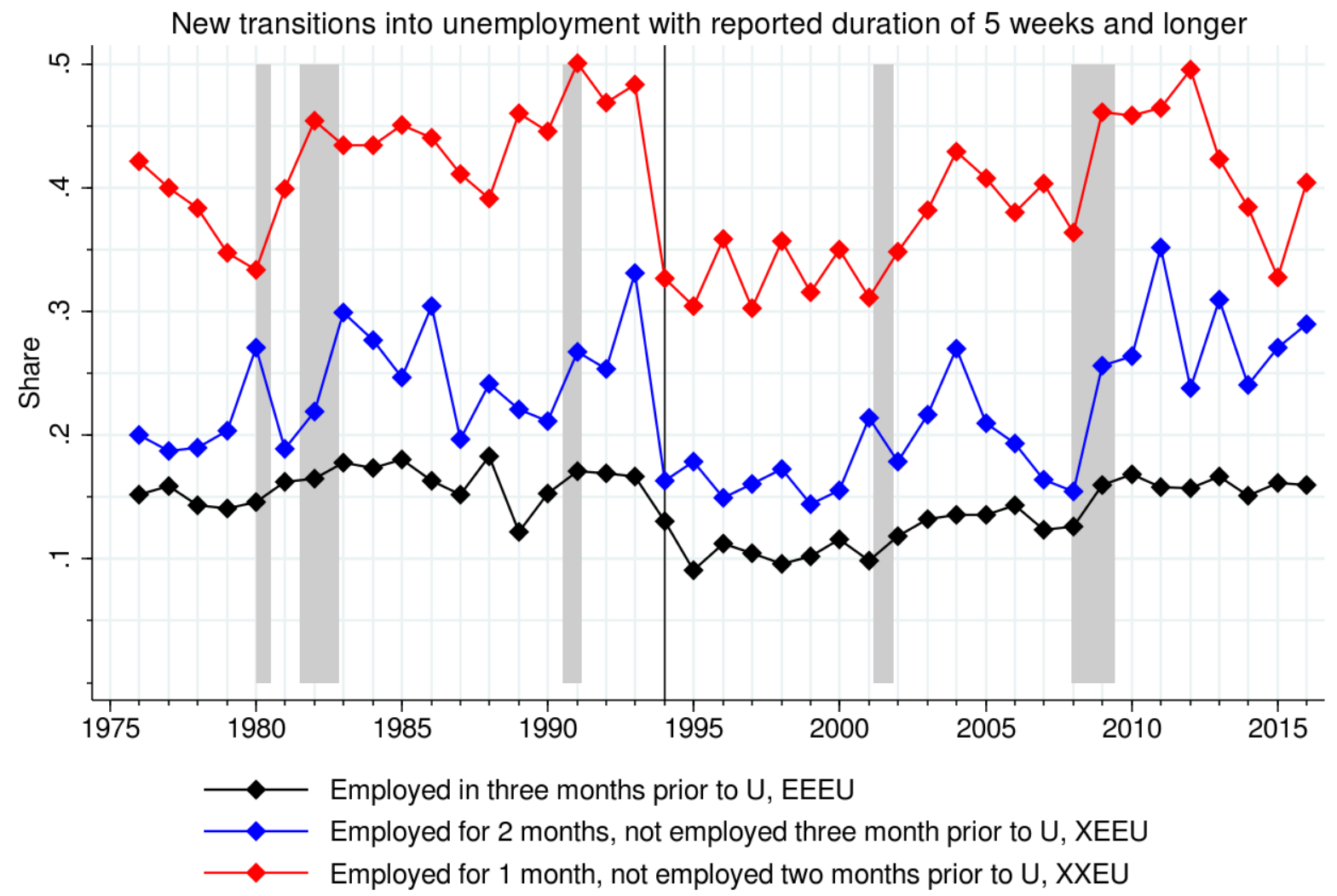

Note: The vertical line shows the 1994 CPS redesign.

Note: The figure shows the incidence of reported long durations of the new employment to unemployment transitions in month four of the four-month CPS panels by length of previous employment. The estimation employs the CPS sampling weights. The shaded areas indicate the NBER recessions. 
Figure 7.3: Unemployment Duration Distribution from Reported Data and from Actual LFS Histories
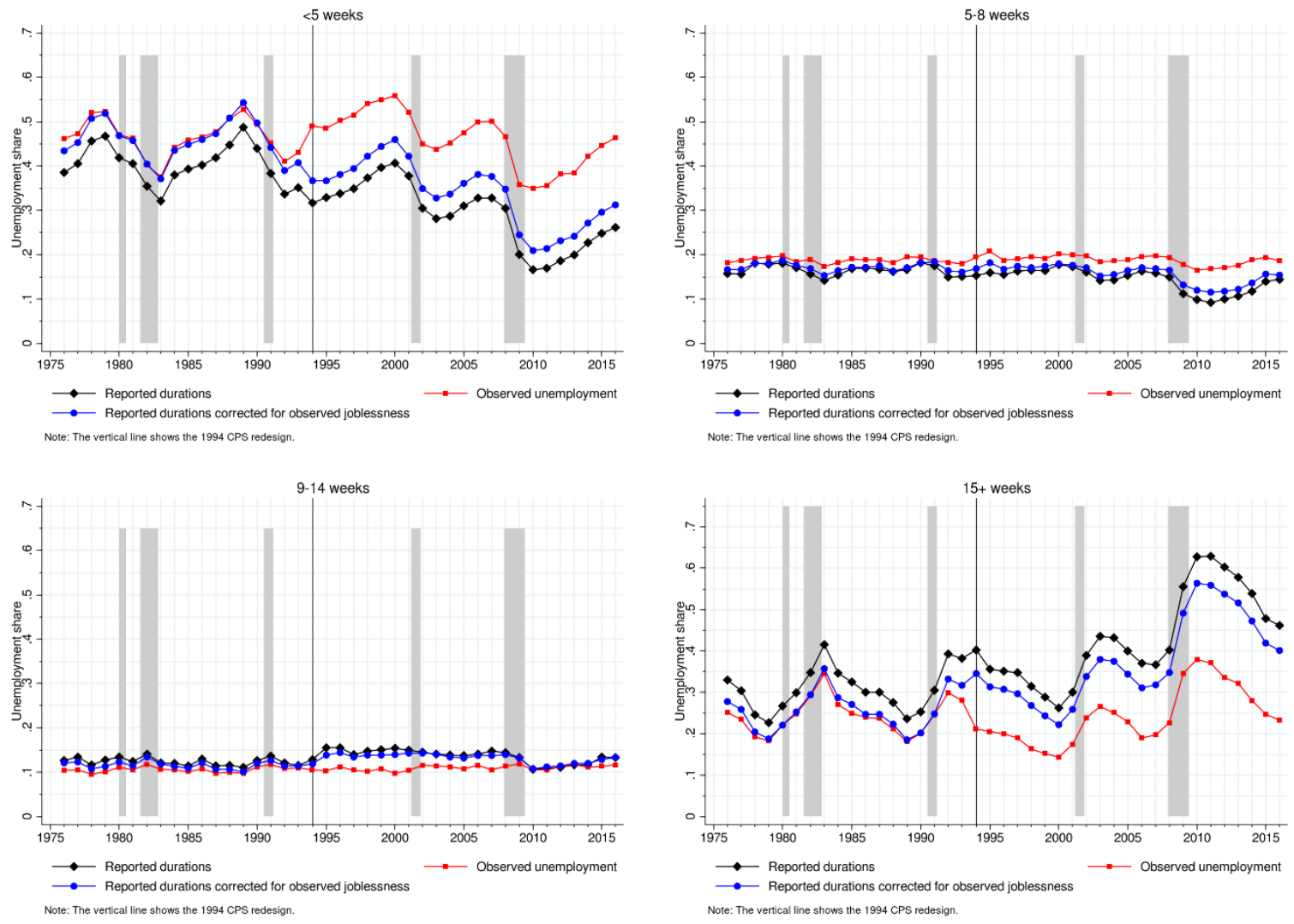

Note: The figure shows the duration distributions of the unemployed in month four of the four-month CPS panels. The reported duration distribution is constructed directly from the reports (black lines). The distribution of observed unemployment in the LFS histories (red lines) is constructed as follows: (1) less than 5 weeks, when the individual is unemployed but employed or OLF in the previous month; (2) 5-8 weeks, when the individual is unemployed in the current and previous months but employed or OLF two months ago; (3) 9-14 weeks, when the individual is unemployed in the current and the two preceding months but employed or OLF three months ago; and, finally, (4) 15 weeks or longer, when the individual is unemployed in the four consecutive months. Our preferred distribution, the distribution of reported durations corrected for previous employment (blue lines) is constructed as follows: (1) if the unemployed was employed in the previous month, we assign duration $<5$ weeks; (2) if the unemployed was either unemployed or OLF in the previous month and employed two months ago, we use his reported duration but topcode it at 5-8 weeks if the reported duration is longer; (3) if the unemployed was either unemployed or OLF in the two previous months and employed three months ago, we use his reported duration but topcode it at 9-14 weeks if the reported duration is longer; (4) if the unemployed for non-employed in the preceding three months, we use his reported duration. We use the CPS sampling weights. The shaded areas indicate the NBER recessions. All four panels share the common y-axis. 


\section{APPENDIX}

Table A3.1: Employment Transition Rates and Population Shares of Retired, Disabled and Others, OLF for Three Consecutive Months

\begin{tabular}{lcc}
\hline \hline \multicolumn{1}{c}{ LFS History } & $\begin{array}{c}\text { Employment } \\
\text { transition rate }\end{array}$ & $\begin{array}{c}\text { Population } \\
\text { share }\end{array}$ \\
\hline & \multicolumn{2}{c}{$1994-2016$} \\
\cline { 2 - 3 } NNN, retired in three consecutive months & 0.006 & $15.35 \%$ \\
NNN, disabled in three consecutive months & 0.007 & $3.96 \%$ \\
The rest of NNN histories & 0.037 & $11.34 \%$ \\
\hline \hline
\end{tabular}

Note: The table shows the sample mean of the annual averages of monthly (discrete) rates and population shares. The sample consists of the four-month CPS panels, restricted to the panels with OLF in months 1 , 2 and 3, 1994-2016. "N" in the histories denote OLF status. All calculations use the CPS sampling weights as described in the text. 
Table A5.1: Employment Transition Rate of the Unemployed and those OLF: Labor Force Status History versus Current-Month Information

\begin{tabular}{|c|c|c|c|c|c|c|}
\hline \multicolumn{7}{|c|}{ Alternative Classifications of the Non-Employed } \\
\hline & (1) & $(2)$ & (3) & $(4)$ & (5) & (6) \\
\hline Current LFS (2 gr) & yes & yes & yes & yes & yes & yes \\
\hline Duration of unemployment (3gr) & $\mathrm{x}$ & yes & yes & yes & yes & yes \\
\hline Reasons for unemployment (6 gr) & $\mathrm{x}$ & yes & yes & yes & yes & yes \\
\hline LM attachment of the OLF (7 gr) & $\mathrm{x}$ & $\mathrm{x}$ & yes & yes & yes & $\mathrm{x}$ \\
\hline LFS histories that end in U (9 gr) & $\mathrm{x}$ & $\mathrm{x}$ & $\mathrm{x}$ & yes & yes & yes \\
\hline LFS histories that end in OLF (9 gr) & $\mathrm{x}$ & $\mathrm{x}$ & $\mathrm{x}$ & $\mathrm{x}$ & yes & yes \\
\hline $\begin{array}{l}\text { Age, education, gender, year, } \\
\text { seasonals, constant }\end{array}$ & yes & yes & yes & yes & yes & yes \\
\hline Observations & $2,188,466$ & $2,188,466$ & $2,188,466$ & $2,188,466$ & $2,188,466$ & $2,188,466$ \\
\hline Adjusted R-squared & 0.074 & 0.099 & 0.108 & 0.115 & 0.189 & 0.187 \\
\hline F stat & 4000 & 4727 & 4668 & 4376 & 7000 & 7512 \\
\hline
\end{tabular}

Note: The sample consists of the four-month CPS panels, restricted to the panels with OLF in month three, 1994-2016. See the notes in Table 5.1 for further details. The estimation employs the CPS sampling weights. 
Table A5.2: Employment Transition Rates of the Non-Employed: Detailed Labor Force Status History versus Past LFS Status

\begin{tabular}{|c|c|c|}
\hline & \multicolumn{2}{|c|}{ " Unemployed + OLF } \\
\hline & Past LFS & $\begin{array}{c}\text { LFS } \\
\text { Histories }\end{array}$ \\
\hline & 1 & 2 \\
\hline LFS Histories (18 gr) & $\mathrm{x}$ & yes \\
\hline \multicolumn{3}{|l|}{ LFS in $t$} \\
\hline $\mathrm{U}$ & $\begin{array}{l}0.0816^{* * * *} \\
\quad(0.0007)\end{array}$ & $\mathrm{x}$ \\
\hline OLF & omitted & $\mathrm{x}$ \\
\hline \multicolumn{3}{|l|}{$L F S$ in $t-1$} \\
\hline $\mathrm{E}$ & $\begin{array}{l}0.212^{* * *} \\
\quad(0.0008)\end{array}$ & $\mathrm{x}$ \\
\hline $\mathrm{U}$ & $\begin{array}{r}0.0292 * * * \\
(0.0008)\end{array}$ & $\mathrm{x}$ \\
\hline OLF & omitted & $\mathrm{x}$ \\
\hline \multicolumn{3}{|l|}{$L F S$ in $t-2$} \\
\hline $\mathrm{E}$ & $\begin{array}{l}0.142 * * * \\
\quad(0.0007)\end{array}$ & $\mathrm{x}$ \\
\hline U & $\begin{array}{r}0.0235 * * * \\
\quad(0.0007)\end{array}$ & $\mathrm{x}$ \\
\hline OLF & omitted & $\mathrm{x}$ \\
\hline $\begin{array}{l}\text { Age, gender, educ, year, } \\
\text { seasonals, cons }\end{array}$ & yes & yes \\
\hline Observations & $2,188,466$ & $2,188,466$ \\
\hline Adjusted R-squared & 0.178 & 0.179 \\
\hline F stat & 9883 & 7973 \\
\hline LR chi2(12) Model1 vs N & odel2 = 3303.6 & \\
\hline
\end{tabular}

Note: The sample consists of the four-month CPS panels, restricted to the panels with OLF in month three, 1994-2016. The estimation employs the CPS sampling weights. 
Table A5.3: Employment Transition Rate of the Unemployed: Labor Force Status History versus Current-Month Information, Alternative Specifications of the Duration of Unemployment

\begin{tabular}{|c|c|c|c|c|c|c|c|c|}
\hline & $\begin{array}{l}\text { Duration } \\
\text { (3groups) }\end{array}$ & $\begin{array}{l}\text { Duration } \\
\text { (contin) }\end{array}$ & $\begin{array}{c}\text { Duration } \\
\text { (3groups)+ } \\
\text { Reason }\end{array}$ & $\begin{array}{c}\text { Duration } \\
\text { (3groups) } \\
\text { X Reason }\end{array}$ & $\begin{array}{c}\text { LFS } \\
\text { Histories + } \\
\text { Duration } \\
\text { (3groups) }\end{array}$ & $\begin{array}{c}\text { LFS } \\
\text { Histories + } \\
\text { Duration } \\
\text { (contin) }\end{array}$ & $\begin{array}{c}\text { LFS } \\
\text { Histories + } \\
\text { Duration } \\
\text { (3groups) + } \\
\text { Reason } \\
\end{array}$ & $\begin{array}{c}\text { LFS } \\
\text { Histories + } \\
\text { Duration } \\
\text { (3groups) } \\
\text { X Reason }\end{array}$ \\
\hline & $(1)$ & $(2)$ & (3) & (4) & $(5)$ & $(6)$ & $(7)$ & $(8)$ \\
\hline LFS Histoires (9 groups) & $\mathrm{x}$ & $\mathrm{x}$ & $\mathrm{x}$ & yes & yes & yes & yes & yes \\
\hline Duration of Ut (3 gr) & yes & $\mathrm{x}$ & yes & yes & yes & $\mathrm{x}$ & yes & yes \\
\hline Duration of Ut (continuous, $\ln$ ) & $\mathrm{x}$ & yes & $\mathrm{x}$ & $\mathrm{x}$ & $\mathrm{x}$ & yes & $\mathrm{x}$ & $\mathrm{x}$ \\
\hline Reason for Ut (6 gr) & $\mathrm{x}$ & $\mathrm{x}$ & yes & $\mathrm{x}$ & $\mathrm{x}$ & $\mathrm{x}$ & yes & yes \\
\hline Duration and Reason for Ut (3X6 gr) & $\mathrm{x}$ & $\mathrm{x}$ & $\mathrm{x}$ & yes & $\mathrm{x}$ & $\mathrm{x}$ & yes & yes \\
\hline $\begin{array}{l}\text { Age, gender, educ, year, seasonals, } \\
\text { cons }\end{array}$ & yes & yes & yes & yes & yes & yes & yes & yes \\
\hline Observations & 191,738 & 191,324 & 191,738 & 191,738 & 191,738 & 191,324 & 191,738 & 191,738 \\
\hline Adjusted R-squared & 0.062 & 0.070 & 0.095 & 0.097 & 0.098 & 0.101 & 0.117 & 0.118 \\
\hline F-stat & 281.5 & 327.9 & 403.9 & 343.5 & 394.6 & 415.3 & 437.0 & 378.3 \\
\hline LR chi2(8) Model 5 vs Model $7=46$ & 8.75 & & & & & & & \\
\hline
\end{tabular}

Note: The sample consists of the four-month CPS panels, restricted to the panels with unemployment in month three, 1994-2016. The regressions are estimated with a constant. When including sets of dummies for LFS histories, duration or reason for unemployment, we omit one category from each classification to avoid multicollinearity. The classification by reported duration of unemployment consists of the three categories: less than 5 weeks, 5-26 weeks, and 27+ weeks. The classification by reason for unemployment consist of six categories: temporary layoff, permanent layoff, temporary job ended, quit, re-entry, and new entry. The demographics controls are a set of 2 dummies for gender, a set of 7 dummies for age, and a set of 4 dummies for education; we omit one category from each set to avoid multicollinearity. The estimation employs the CPS sampling weights. 
Table A6.1: Self-Reported Labor Market Attachment and LFS Histories of those OLF, Average Shares in 1994-2016

Panel A. Self-Reported Labor Market Attachment by LFS History

\begin{tabular}{lrrrrrrrrr}
\hline \hline & \multicolumn{10}{c}{ LFS History } \\
\cline { 2 - 9 } & EEN & UEN & NEN & EUN & ENN & NUN & UNN & UUN & NNN \\
\hline Want job & & & & & & & & & \\
$\quad$ Marg. attach., discouraged & $1.2 \%$ & $5.0 \%$ & $0.8 \%$ & $7.0 \%$ & $0.9 \%$ & $6.2 \%$ & $5.1 \%$ & $10.6 \%$ & $0.3 \%$ \\
$\quad$ Marg. attach., other & $1.8 \%$ & $6.6 \%$ & $1.7 \%$ & $9.9 \%$ & $1.6 \%$ & $11.3 \%$ & $7.7 \%$ & $14.5 \%$ & $0.5 \%$ \\
$\quad$ Other & $16.6 \%$ & $26.9 \%$ & $10.2 \%$ & $26.9 \%$ & $8.2 \%$ & $22.0 \%$ & $16.5 \%$ & $25.4 \%$ & $2.9 \%$ \\
Do not want job & & & & & & & & & \\
$\quad$ Other & $36.5 \%$ & $32.8 \%$ & $35.2 \%$ & $32.4 \%$ & $31.5 \%$ & $29.3 \%$ & $33.0 \%$ & $28.7 \%$ & $18.3 \%$ \\
$\quad$ In school, 16-24 y o & $19.1 \%$ & $19.2 \%$ & $24.3 \%$ & $14.5 \%$ & $21.8 \%$ & $21.1 \%$ & $20.5 \%$ & $12.6 \%$ & $10.3 \%$ \\
$\quad$ Disabled & $6.3 \%$ & $3.8 \%$ & $6.4 \%$ & $3.9 \%$ & $9.9 \%$ & $4.0 \%$ & $9.4 \%$ & $4.3 \%$ & $15.3 \%$ \\
$\quad$ Retired & $18.4 \%$ & $5.7 \%$ & $21.3 \%$ & $5.5 \%$ & $26.1 \%$ & $6.0 \%$ & $7.7 \%$ & $3.9 \%$ & $52.5 \%$ \\
\hline All & $100 \%$ & $100 \%$ & $100 \%$ & $100 \%$ & $100 \%$ & $100 \%$ & $100 \%$ & $100 \%$ & $100 \%$ \\
\hline \hline
\end{tabular}

Panel B. Composition of Self-Reported Labor Market Attachment by LFS History

\begin{tabular}{|c|c|c|c|c|c|c|c|}
\hline \multirow[b]{3}{*}{ LFS Histories } & \multicolumn{7}{|c|}{$\begin{array}{c}\text { Self-Reported Labor Market Attachment } \\
\end{array}$} \\
\hline & \multicolumn{3}{|c|}{ Want job } & \multicolumn{4}{|c|}{ Do not want job } \\
\hline & $\begin{array}{l}\text { Marg. } \\
\text { attach., } \\
\text { discoura } \\
\text { ged }\end{array}$ & $\begin{array}{l}\text { Marg. } \\
\text { attach., } \\
\text { other }\end{array}$ & $\begin{array}{l}\text { Want } \\
\text { job, } \\
\text { other }\end{array}$ & $\begin{array}{l}\text { Not in } \\
\text { school, } \\
\text { retired } \\
\text { or } \\
\text { disabled }\end{array}$ & $\begin{array}{c}\text { In } \\
\text { school } \\
16-24 \text { y } \\
\text { o }\end{array}$ & Disabled & Retired \\
\hline \multicolumn{8}{|l|}{ Recently employed } \\
\hline EEN & $6.6 \%$ & $5.7 \%$ & $12.1 \%$ & $5.8 \%$ & $5.8 \%$ & $1.4 \%$ & $1.2 \%$ \\
\hline ENN & $5.2 \%$ & $5.1 \%$ & $6.2 \%$ & $5.2 \%$ & $6.5 \%$ & $2.3 \%$ & $1.8 \%$ \\
\hline NEN & $1.5 \%$ & $1.9 \%$ & $2.6 \%$ & $1.9 \%$ & $2.5 \%$ & $0.5 \%$ & $0.5 \%$ \\
\hline EUN & $4.2 \%$ & $3.3 \%$ & $2.2 \%$ & $0.6 \%$ & $0.5 \%$ & $0.1 \%$ & $0.0 \%$ \\
\hline UEN & $1.6 \%$ & $1.3 \%$ & $1.2 \%$ & $0.3 \%$ & $0.4 \%$ & $0.0 \%$ & $0.0 \%$ \\
\hline \multicolumn{8}{|c|}{ No recent employment } \\
\hline UNN & $14.7 \%$ & $12.2 \%$ & $6.3 \%$ & $2.8 \%$ & $3.0 \%$ & $1.1 \%$ & $0.3 \%$ \\
\hline UUN & $18.1 \%$ & $13.7 \%$ & $5.8 \%$ & $1.4 \%$ & $1.1 \%$ & $0.3 \%$ & $0.1 \%$ \\
\hline NUN & $10.4 \%$ & $11.0 \%$ & $5.0 \%$ & $1.5 \%$ & $1.9 \%$ & $0.3 \%$ & $0.1 \%$ \\
\hline NNN & $37.6 \%$ & $45.8 \%$ & $58.6 \%$ & $80.6 \%$ & $78.2 \%$ & $94.1 \%$ & $96.0 \%$ \\
\hline All & $100.0 \%$ & $100.0 \%$ & $100.0 \%$ & $100.0 \%$ & $100.0 \%$ & $100.0 \%$ & $100.0 \%$ \\
\hline
\end{tabular}

Note: See Section 6. 
Figure A3.1: LFS Histories of the Non-Employed: Employment Transition Rates and Population Shares, 1976-2016

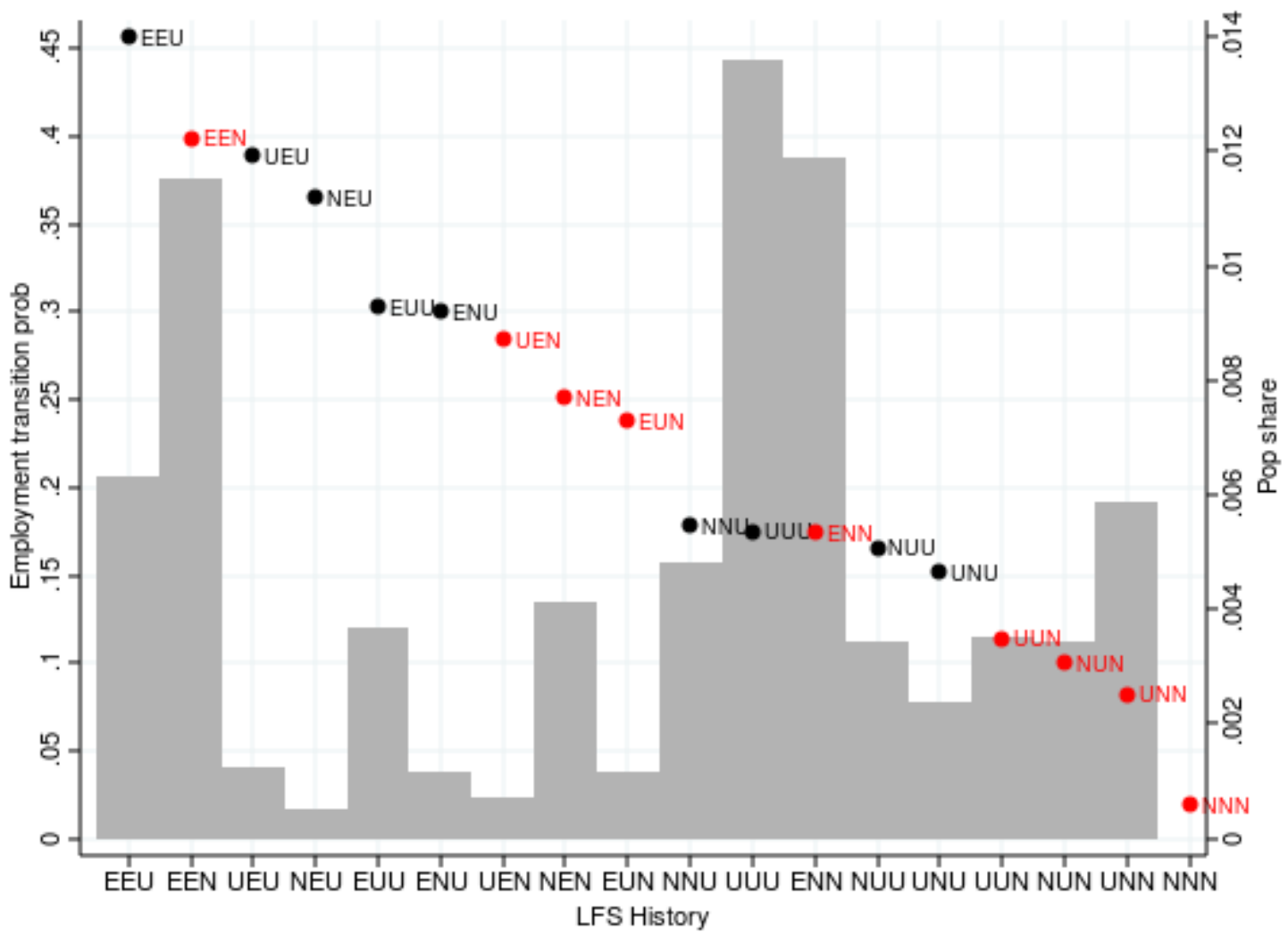

Note: The figure shows average employment transition rates (black dots for U-histories and red dots for Nhistories, left axis) and pop. shares (gray bars, right axis) by the labor force status history of the nonemployed, 1976-2016. The pop. share of NNN is 31.1.\% (not shown). The LFS histories on the x-axis are ranked by the employment transition rates. 
Figure A3.2: Population Shares of the Non-Employed, by Labor Force Status History, Annual Averages of Monthly Shares

Panel A. LFS Histories with Recent Employment

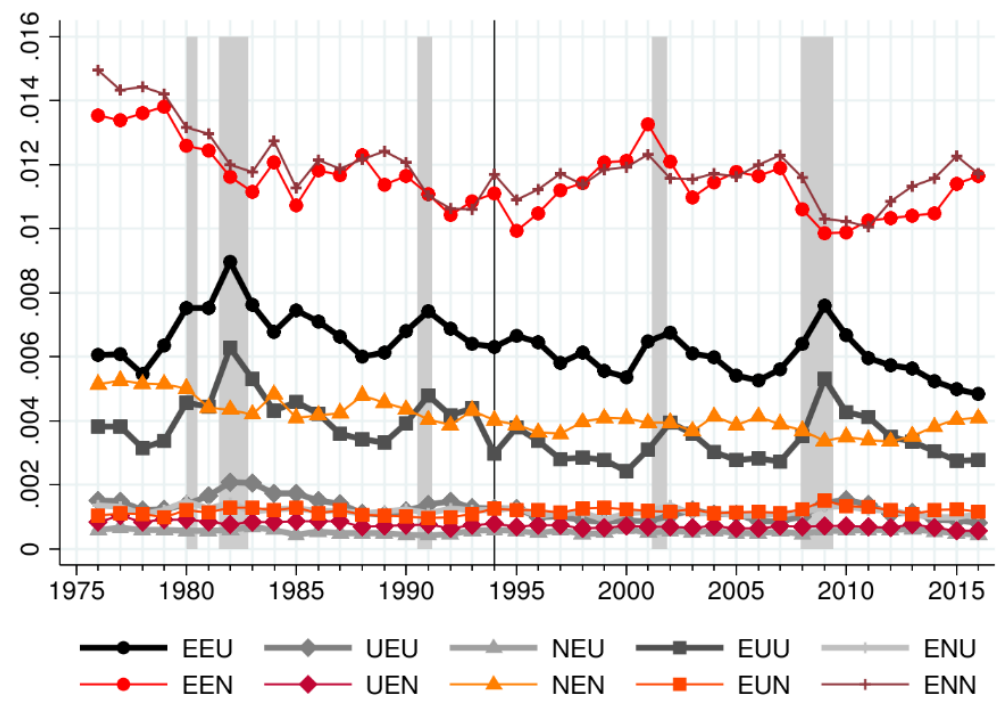

Panel B. LFS Histories with No Recent Employment, Except NNN

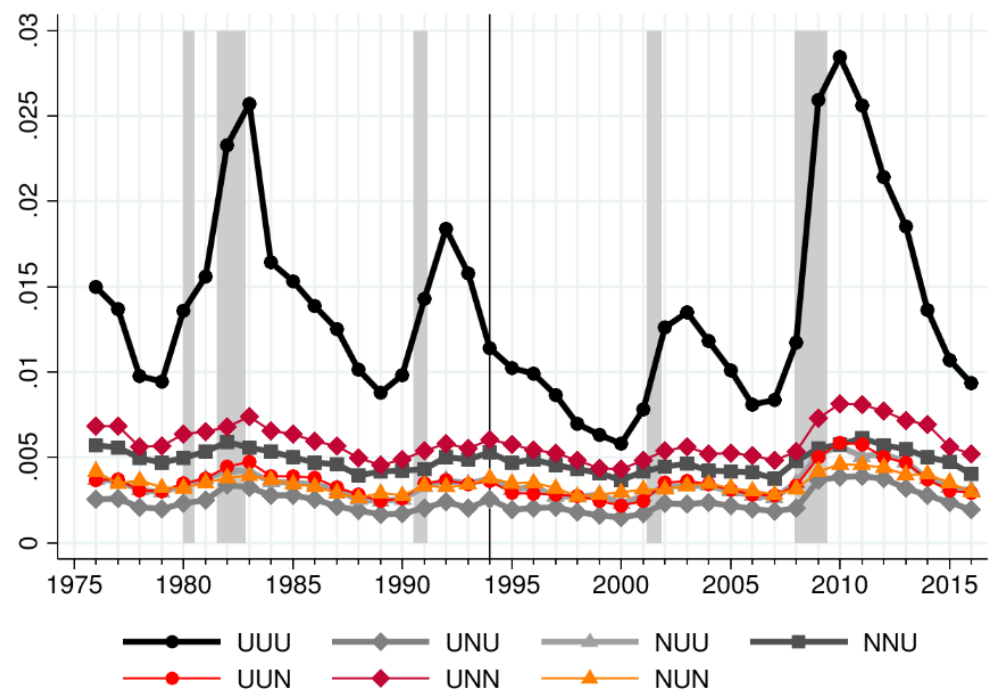

Note: The figure shows shares in the civilian noninstitutionalized population 16 years and older. The sample consists of the four-month CPS panels, restricted to the panels with non-employment (unemployment or OLF) in month three. We use the CPS sampling weights. The vertical line shows the 1994 CPS redesign year. 
Figure A3.3: Employment Transition Rates of the Non-Employed, by Labor Force Status History, Annual Averages of Monthly Rates

Panel A. LFS Histories with Recent Employment (Selected histories)

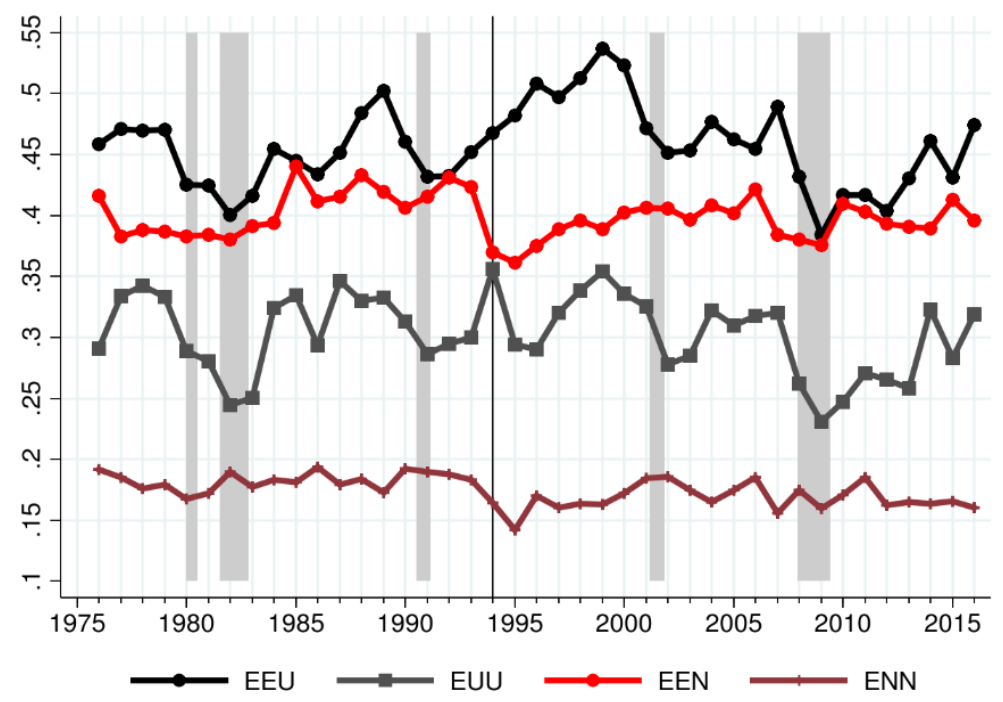

Panel B. LFS Histories with No Recent Employment

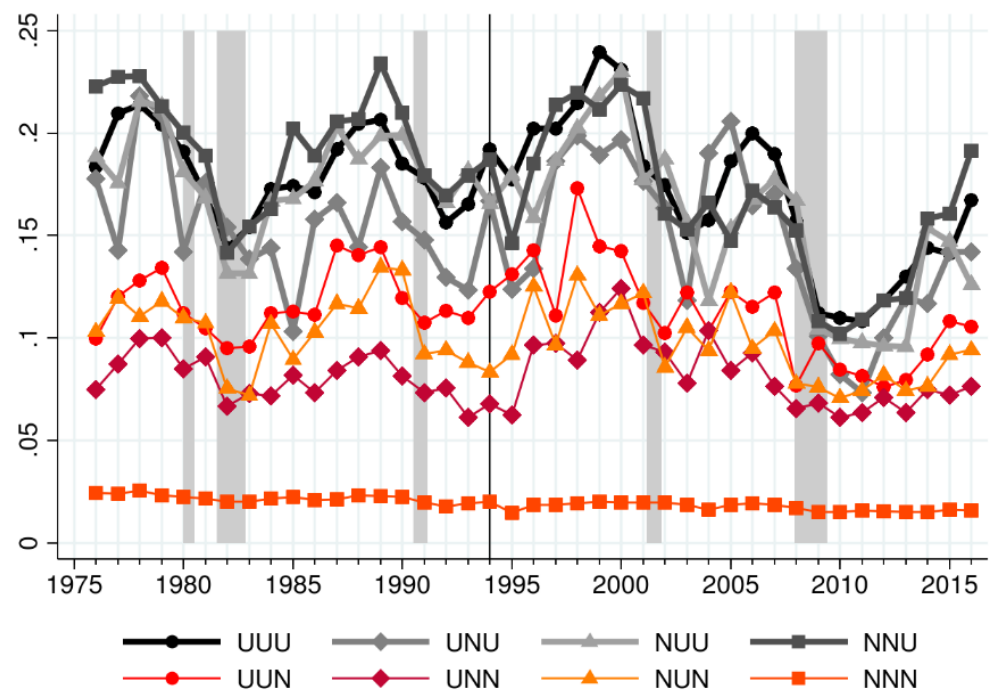

Note: The sample consists of the four-month CPS panels, restricted to the panels with non-employment (unemployment or OLF) in month three. "E" in the histories denotes employment, "U" - unemployment, and "N" - OLF. All calculations use the CPS sampling weights as described in the text. The vertical line shows the 1994 CPS redesign year. 
Figure A3.4: Employment Transition Rates of the Unemployed and OLF, by LFS in the Last Two Months

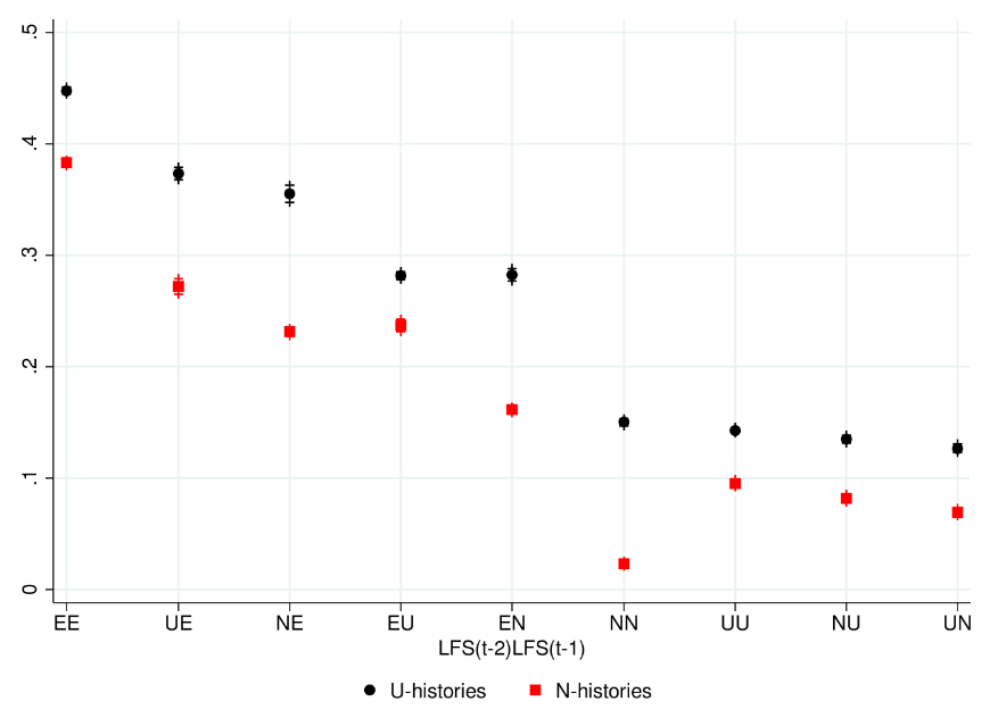

Note: The figure shows the coefficient estimates and the 95\% confidence intervals from the regression in Table 3.3.

Figure A3.5: Employment Transition Rates with and without Temporary Layoffs

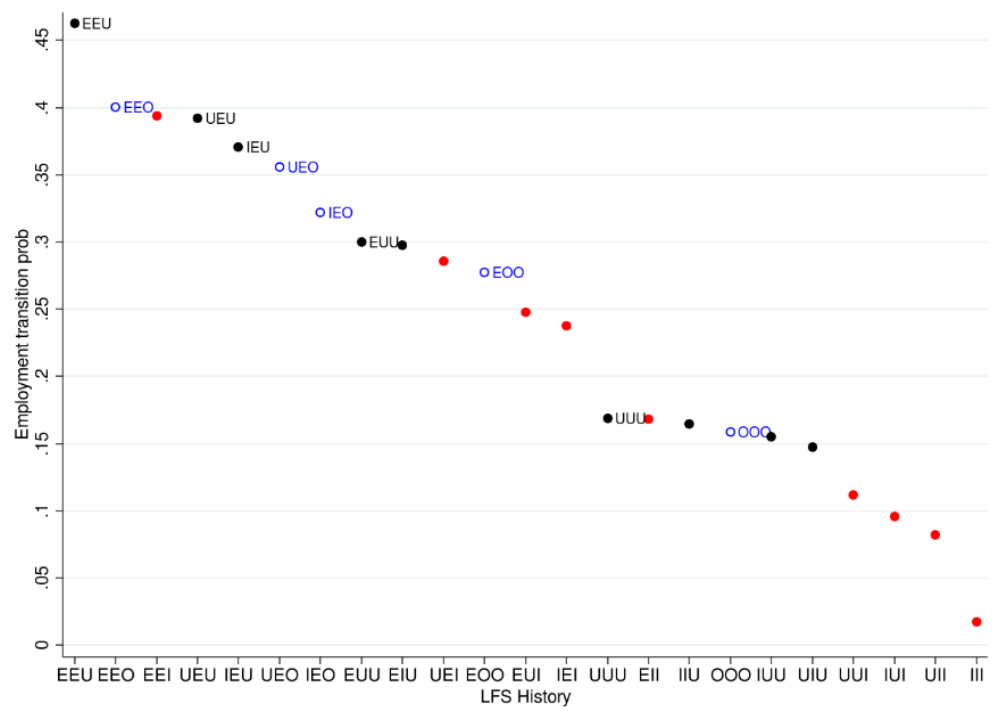

Note: The figure shows the sample mean of the annual averages of monthly (discrete) rates. The sample consists of the four-month CPS panels, restricted to the panels with non-employment (unemployment or OLF) in month three, 1994-2016. "E" in the histories denotes employment, "U" - unemployment, "N" - OLF, and "O" denotes the unemployed for reasons other than temporary layoffs. All calculations use the CPS sampling weights as described in the text. 
Figure A3.6: Employment Transition Rates and Population Shares of Retired, Disabled and Others OLF for Three Consecutive Months

\section{A. Employment Transition rates}

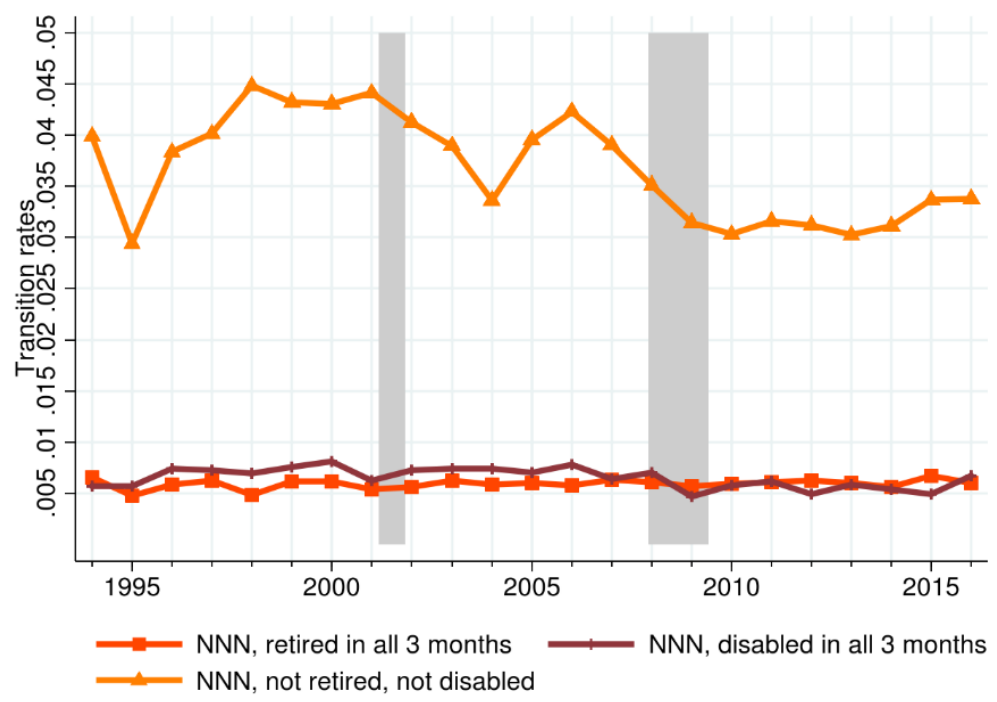

B. Population shares

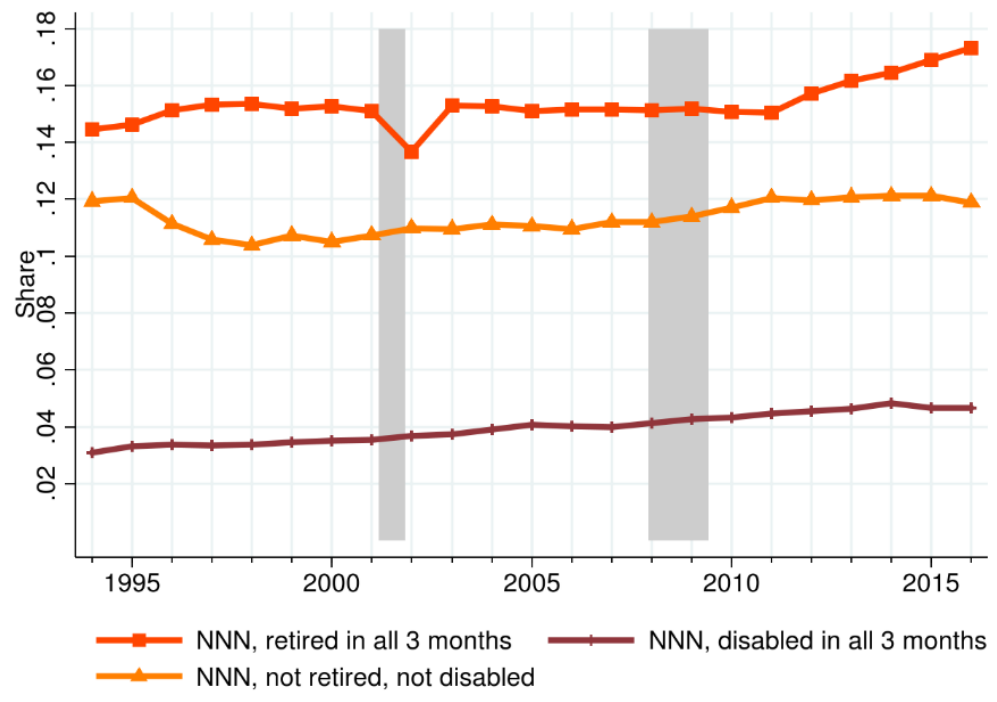

Note: The figure shows the sample mean of the annual averages of monthly (discrete) rates and population shares. The sample consists of the four-month CPS panels, restricted to the panels with non-employment (unemployment or OLF) in month three, 1994-2016. "N" in the histories denotes OLF status. All calculations use the CPS sampling weights as described in the text. 
Figure A7.1: Inconsistency of Reported Unemployment Durations and Observed LFS

Panel A. Share of the Unemployed Who Report Durations Longer Than 5 Weeks, Conditional On Employment in the Previous Month

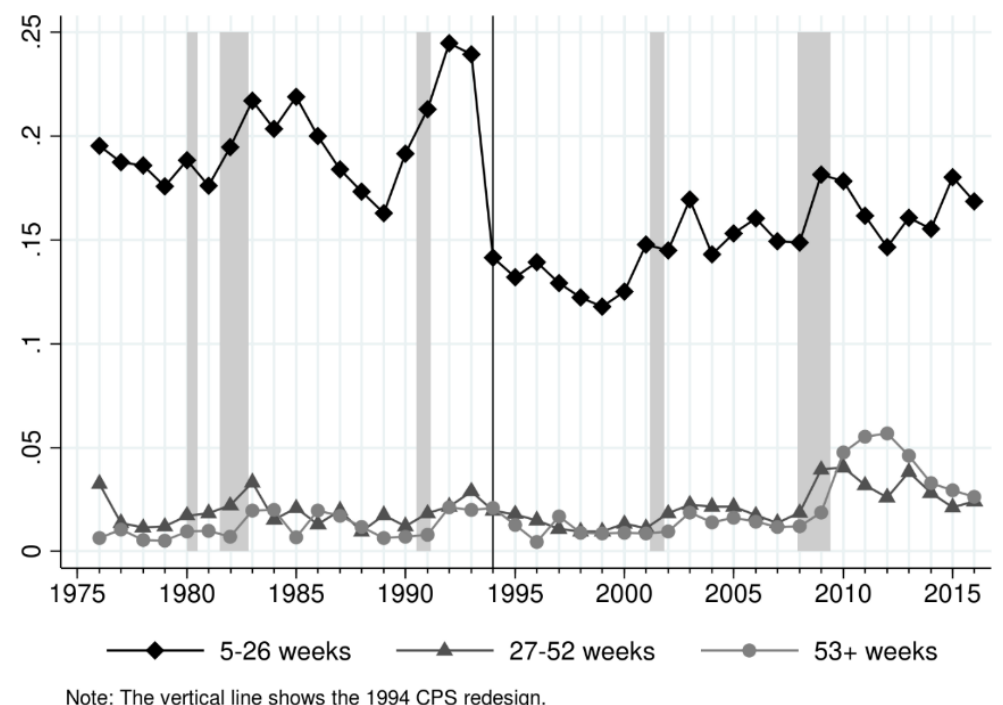

Panel B. Share of the Unemployed Who Report Durations Longer Than 5 Weeks, Conditional On OLF in the Previous Month

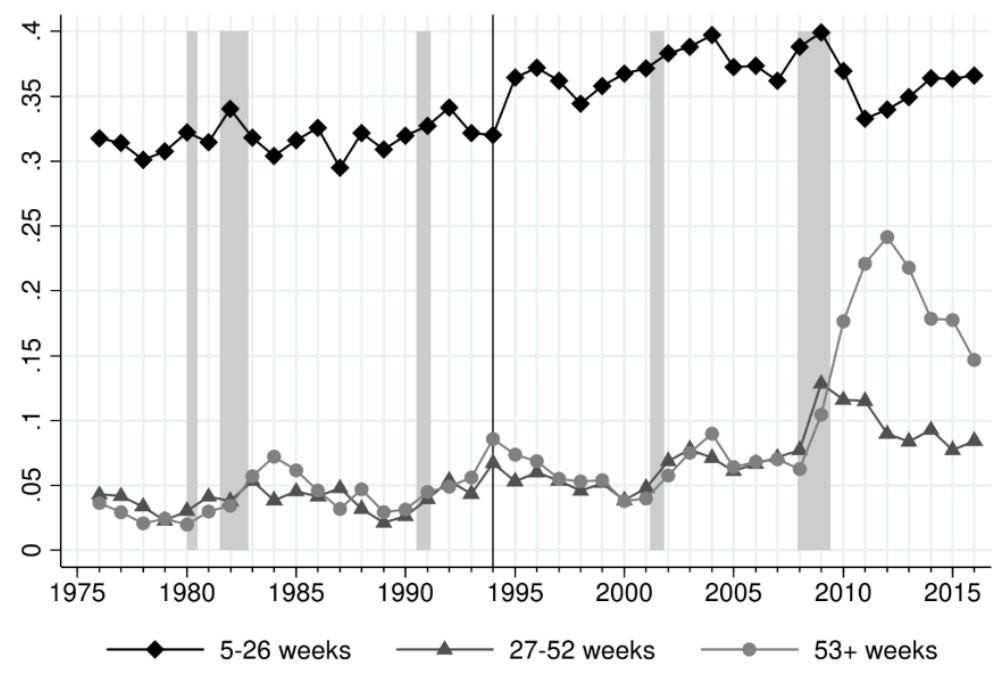

Note: The vertical line shows the 1994 CPS redesign.

Note: The sample consists of the four-month CPS panels, restricted to the panels with "Unemployment" in month three. We employ the CPS sampling weights. 
Figure A7.2: Mean and Median of Reported Durations among New Transitions from Employment to Unemployment with Reported Durations of 5+ Weeks by Length of Previous Employment

Panel A. Mean

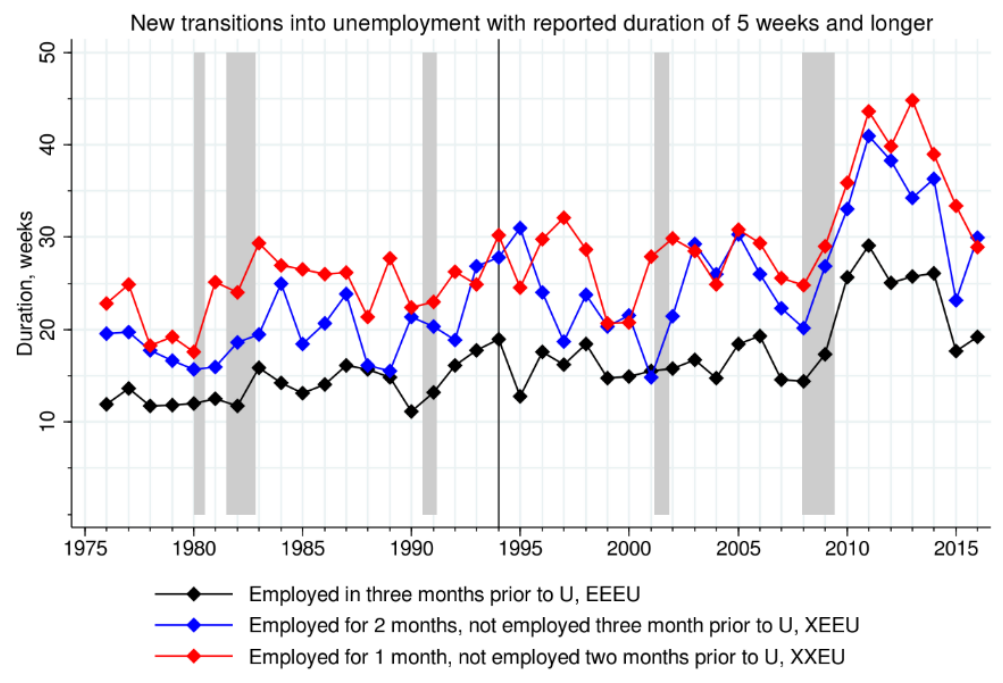

Note: The vertical line shows the 1994 CPS redesign.

Panel B. Median

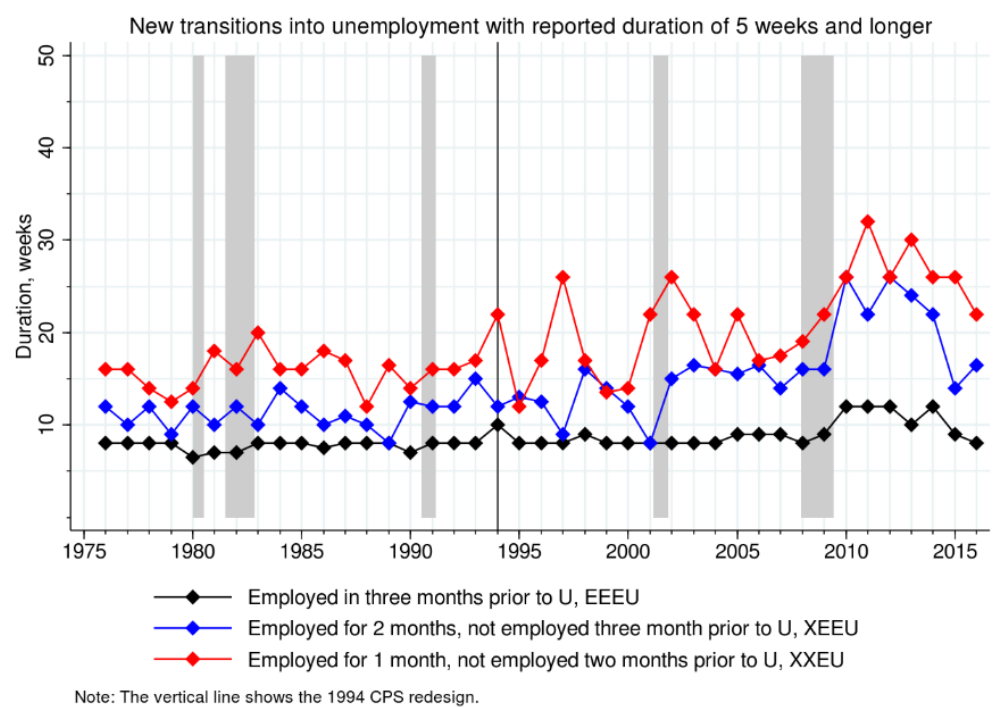

Note: The figure shows the mean and median of the longer reported durations (5+ weeks) for new employment to unemployment transitions in month four of the four-month CPS panels, by the length of previous employment. We employ the CPS sampling weights. The shaded areas indicate the NBER recessions. 
Figure A7.3: Distribution of Reported Durations of the Newly Unemployed from Employment and from OLF
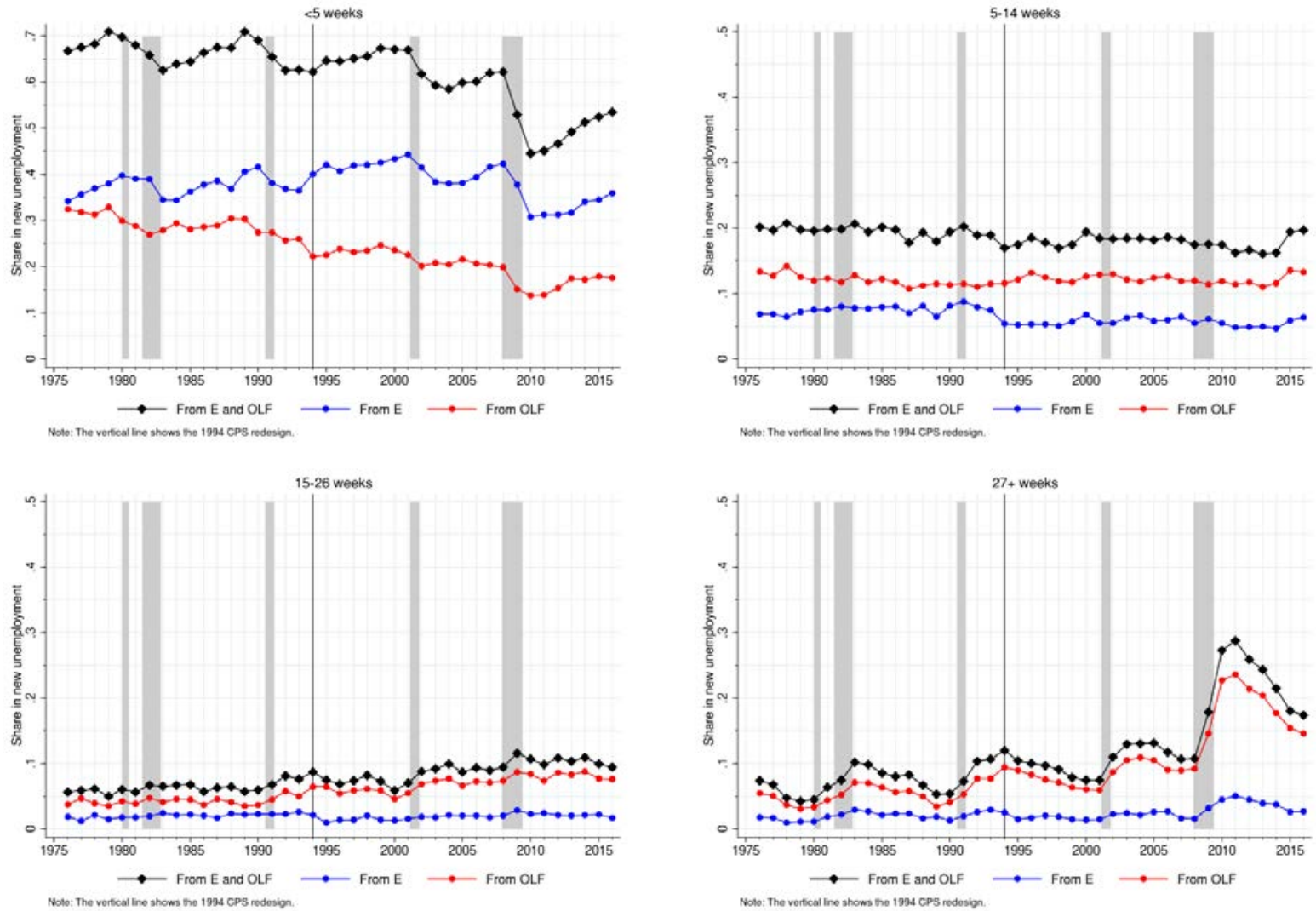

Note: The figure shows the duration distribution for the newly unemployed in month four of the four-month CPS panels, i.e., those who were employed or OLF in month three. The shaded areas indicate the NBER recessions. All four panels share the common y-axis. 
Figure A7.4: Monthly Job Finding Rate Constructed from Short-Term Unemployment Using Shimer's (2012) Formula

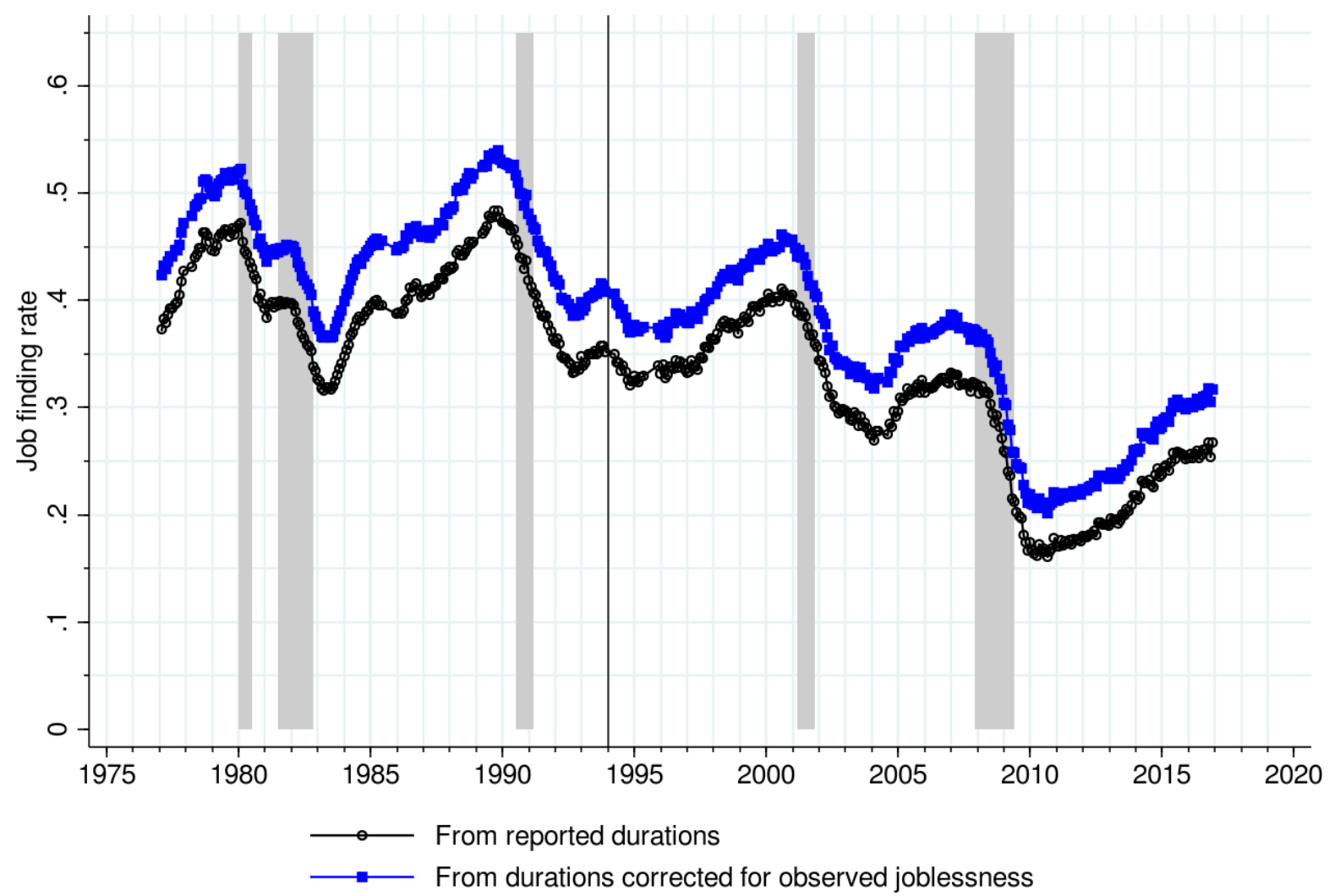

Note: The vertical line shows the 1994 CPS redesign.

Note: The figure shows the job finding rate calculated from the two alternative distributions of unemployment durations: from reported durations corrected for observed joblessness (our preferred one, blue squares) and the conventional self-reported duration of unemployment (black circles), 1976-2016. We employ the CPS sampling weights. The shaded areas indicate the NBER recessions. 